\title{
The Mount Sinai Hospital Institute for critical care medicine response to the COVID-19 pandemic
}

\author{
Jennifer Wang ${ }^{1,2}$, Evan Leibner ${ }^{1,3}$, Jaime B. Hyman ${ }^{4}$, Sanam Ahmed ${ }^{1,2}$, Joshua Hamburger ${ }^{4}$, Jean Hsieh ${ }^{1,5}$, \\ Neha Dangayach ${ }^{1,6}$, Pranai Tandon ${ }^{1,5}$, Umesh Gidwani ${ }^{1,7}$, Andrew Leibowitz ${ }^{4}$, Roopa Kohli-Seth ${ }^{1,2}$; \\ On behalf of Mount Sinai Anesthesiology and Critical Care COVID19 Writing Group
}

${ }^{1}$ Institute for Critical Care Medicine, Departments of ${ }^{2}$ Surgery, ${ }^{3}$ Emergency Medicine, and ${ }^{4}$ Anesthesiology, Perioperative, and Pain Medicine, ${ }^{5}$ Division of Pulmonary Medicine, ${ }^{6}$ Department of Neurosurgery, and ${ }^{7}$ Division of Cardiology, Icahn School of Medicine at Mount Sinai, New York, NY, USA

Background: The coronavirus disease 2019 (COVID-19) pandemic resulted in a surge of critically ill patients. This was especially true in New York City. We present a roadmap for hospitals and healthcare systems to prepare for a Pandemic.

Methods: This was a retrospective review of how Mount Sinai Hospital (MSH) was able to rapidly prepare to handle the pandemic. MSH, the largest academic hospital within the Mount Sinai Health System, rapidly expanded the intensive care unit (ICU) bed capacity, including creating new ICU beds, expanded the workforce, and created guidelines.

Results: MSH a 1,139-bed quaternary care academic referral hospital with 104 ICU beds expanded to 1,453 beds (27.5\% increase) with 235 ICU beds (126\% increase) during the pandemic peak in the first week of April 2020. From March to June 2020, with follow-up through October 2020, MSH admitted 2,591 COVID-19-positive patients, 614 to ICUs. Most admitted patients received noninvasive support including a non-rebreather mask, high flow nasal cannula, and noninvasive positive pressure ventilation. Among ICU patients, $68.4 \%(n=420)$ received mechanical ventilation; among the admitted ICU patients, 42.8\% $(n=263)$ died, and $47.8 \%(n=294)$ were discharged alive.

Conclusions: Flexible bed management initiatives; teamwork across multiple disciplines; and development and implementation of guidelines were critical accommodating the surge of critically ill patients. Non-ICU services and staff were deployed to augment the critical care work force and open new critical care units. This approach to rapidly expand bed availability and staffing across the system helped provide the best care for the patients and saved lives.

Key Words: COVID-19; critical care; pandemics; surge capacity

\section{INTRODUCTION}

Severe acute respiratory syndrome coronavirus 2 (SARS-CoV-2) is a novel respiratory virus of the Coronaviridae family of enveloped, single-stranded RNA viruses and caused the coronavirus disease 2019 (COVID-19). First identified in China in December 2019, COVID-19 became a pandemic in 2020, leading to the largest public health crisis in decades. The first COVID-19 case in the United States (US) was reported in January 2020. By March 2020, COVID-19 cases were identified in all 50 states, District of Columbia, Puerto Rico, Guam, Northern

\section{Original Article}

Received: April 6, 2021

Revised: June 29, 2021

Accepted: July 1, 2021

Corresponding author

Evan Leibner

Institute for Critical Care Medicine,

Mount Sinai Hospital, 1468 Madison

Ave, New York, NY 10029, USA

Tel: + 1-212-241-8867

Fax: +1-212-860-3669

E-mail: evan.leibner@mountsinai.org

Copyright $\odot 2021$ The Korean Society of Critical Care Medicine

This is an Open Access article distributed under the terms of Creative Attributions Non-Commercial License (https:/I

creativecommons.org/li-censes/by-nc/4.0/) which permits unrestricted noncommercial use, distribution, and reproduction in any medium, provided the original work is properly cited. 
Marianas, and the US Virgin Islands.

New York City (NYC) was the epicenter of the US COVID-19 outbreak. As of February 22, 2021, there were 1,590,000 diagnosed cases and 46,346 deaths [1]. The rapid increase in cases necessitated an unprecedented increase in critical care capacity and development of institutional guidelines for COVID-19 care. In the present study, how increased ICU capacity and the process for creating, disseminating, and revising guidelines for critically ill COVID-19 patients at Mount Sinai Health System (MSHS) are discussed. The aim is to provide a possible roadmap for other institutions to quickly scale up resources for managing critically ill COVID-19 patients.

\section{MATERIALS AND METHODS}

This was a retrospective review of the response of Mount Sinai Hospital to the COVID-19 pandemic and was exempt from IRB Review. The present manuscript was descriptive in design to explain the efforts made by the Mount Sinai Hospital (MSH) to prepare for the COVID-19 pandemic. Because no patients were involved in policy initiative for the COVID surge management, IRB approval was not required.

\section{KEY MESSAGES}

- This review provides a roadmap for hospitals and health systems on how to prepare for a surge in critical care capacity.

- The coronavirus disease 2019 pandemic requires a team effort across multiple disciplines to manage a surge of critically ill patients.

MSHS, comprised of the Icahn School of Medicine at MSH and eight hospitals with more than 3,800 inpatient beds and more than 42,000 employees, is one the largest health systems in the US. The Institute for Critical Care Medicine (ICCM) at MSH is comprised of seven adult ICUs with over 6,000 admissions annually as well as several team-based services. The ICCM led the COVID-19 critical care response within MSH. More than 45 critical care faculty within the ICCM are responsible for staffing subspecialty ICUs and include several teams such as the rapid response team (RRT), vascular access team, difficult airway response team (DART), patient safety quality team, clinical research team, and post-ICU recovery clinic.

Providing care for a rapidly increasing number of critically

Table 1. Pre-COVID-19 and COVID-19 ICU beds at Mount Sinai Hospital

\begin{tabular}{|c|c|c|c|c|}
\hline \multirow{2}{*}{ Unit } & \multicolumn{2}{|l|}{ Pre-COVID-19 } & \multicolumn{2}{|l|}{ COVID-19 } \\
\hline & Patient population & No. of beds & Patient population & No. of beds ${ }^{a}$ \\
\hline \multicolumn{5}{|l|}{ PACU } \\
\hline Main OR PACU & OR Post Op & 30 & MICU/SICU/medicine stepdown (COVID negative) & 30 \\
\hline Annenberg 6 PACU & Ambulatory Post $0 p$ & 12 & Transplant critically III (COVID negative) & 12 \\
\hline Annenberg 7 PACU & Neurosurgical Post Op & 12 & OR PACU (COVID negative) & 12 \\
\hline \multicolumn{5}{|l|}{ ICU } \\
\hline MICU & Medical critically ill & 14 & COVID-19 critically ill & 28 \\
\hline SICU & Surgical critically ill & 14 & COVID-19 critically ill & 28 \\
\hline TICU & Transplant critically ill & 12 & COVID-19 critically ill & 24 \\
\hline $\mathrm{CICU}$ & Cardiac critically ill & 14 & COVID-19 critically ill & 28 \\
\hline NSICU & Neurosurgical critically ill & 18 & COVID-19 critically ill & 36 \\
\hline $\mathrm{CVU}$ & Cardiac surgical Critically ill & 14 & COVID-19 critically ill & 28 \\
\hline CTICU & Cardiac surgical Critically ill & 12 & COVID-19 critically ill & 24 \\
\hline \multicolumn{5}{|l|}{ Step down unit } \\
\hline Medicine stepdown & Medicine stepdown & 14 & COVID-19 critically ill & 14 \\
\hline Cardiac stepdown & Cardiac stepdown & 6 & COVID-19 critically ill & 12 \\
\hline Surgical stepdown & Surgical stepdown & 14 & COVID-19 critically ill & 14 \\
\hline Medicine overflow & General medicine patients & 16 & Neurosurgical critically ill & 16 \\
\hline
\end{tabular}

COVID-19: coronavirus disease 2019; ICU: intensive care unit; PACU: post-anesthesia care unit; OR: operating room; Post Op: postoperative patients; MICU: medical ICU; SICU: surgical ICU; TICU: transplant ICU; CICU: cardiac ICU; NSICU: neuroscience ICU; CVU: cardio vascular; CTICU: cardio thoracic ICU. a $\mathrm{CU}$ rooms were set up for two patients but varied depending on patient needs and nursing staff. 
ill patients with acute respiratory failure due to a highly contagious viral illness requires guidelines to inform care and maximize healthcare provider safety. ICCM, Department of Emergency Medicine, Department of Anesthesiology, Perioperative and Pain Medicine, and the Infection Prevention team helped develop guidelines by referencing and adapting professional society guidelines. These guidelines were continuously revised and published on a systemwide COVID-19 website accessible to all hospital employees without the need for in-network access.

\section{RESULTS}

COVID-19 rapidly became a worldwide pandemic with over 111 million confirmed cases and over 2.47 million deaths in 188 countries/regions [1]. MSHS and MSH rapidly adapted to the surge in critically ill patients. MSH expanded from a 1,139bed quaternary care academic referral hospital with 104 ICU beds to 1,453 beds with 235 ICU beds during the pandemic peak (Table 1), which occurred the first week of April (Figure 1). From March to May 2020, MSH admitted 2,161 COVID19-positive patients, 541 to ICUs. Most admitted patients received noninvasive ventilatory support including a non-rebreather mask, high flow nasal cannula, and noninvasive positive pressure ventilation. Among ICU patients, $68.4 \%$ received mechanical ventilation, and among 420 patients that were intubated, $55.0 \%$ died and $43.1 \%$ were discharged alive. Among the 614 patients admitted to the ICU, $42.8 \%$ died and $47.8 \%$ were discharged alive (as of Oct 19, 2020) (Table 2). Advanced age correlated with increased death and likelihood of intubation (Table 3).
Table 2. Clinical characteristics and outcomes of COVID-19 patients admitted to Mount Sinai Hospital

\begin{tabular}{|c|c|c|c|}
\hline Variable & Total & $\begin{array}{l}\text { Never } \\
\text { ICU }\end{array}$ & $\begin{array}{c}\text { Admitted } \\
\text { to ICU }\end{array}$ \\
\hline Demographics & $(n=2,591)$ & $(n=1,977)$ & $(n=614)$ \\
\hline Age (yr) & $60.1 \pm 17.5$ & $60.1 \pm 17.9$ & $60.0 \pm 16.0$ \\
\hline Male & $1,457(56.2)$ & $1,073(54.2)$ & $384(62.5)$ \\
\hline Major comorbidity & $(n=2,494)$ & $(n=1,904)$ & $(n=590)$ \\
\hline HTN & 847 (33.9) & $671(35.2)$ & $176(23.2)$ \\
\hline Diabetes & $553(22.2)$ & 416 (21.8) & 137 (23.2) \\
\hline Obesity & $250(10.0)$ & 199 (10.5) & $51(8.6)$ \\
\hline CKD & $326(13.1)$ & $262(13.7)$ & $64(10.8)$ \\
\hline COPD & 99 (3.9) & $85(4.5)$ & $14(2.4)$ \\
\hline Noninvasive support & $(n=2,291)$ & $(n=1,682)$ & $(n=609)$ \\
\hline NRB & $858(37.4)$ & $507(30.1)$ & $351(57.7)$ \\
\hline HFNC & $353(15.4)$ & 154 (9.2) & $199(32.7)$ \\
\hline NIPPV & $298(13.0)$ & $108(6.4)$ & $190(31.1)$ \\
\hline Invasive ventilator & $(n=2,591)$ & $(n=1,977)$ & $(n=614)$ \\
\hline Intubated & $420(16.2)$ & 0 & $420(68.4)$ \\
\hline Clinical outcome & $(n=2,591)$ & $(n=1,977)$ & $(n=614)$ \\
\hline Died & $485(18.7)$ & $222(11.2)$ & 263 (42.8) \\
\hline Discharged from index visit & $2,051(79.1)$ & $1,757(88.8)$ & $294(47.8)$ \\
\hline Discharged home & $1,623(62.6)$ & $1,435(72.6)$ & 188 (30.6) \\
\hline Discharged to facility & $428(15.6)$ & $322(16.3)$ & $106(17.2)$ \\
\hline Among intubated patients & & & $(n=420)$ \\
\hline Died & & & $231(55.0)$ \\
\hline Discharged from index visit & & & $181(43.1)$ \\
\hline Discharged home & & & $80(19.0)$ \\
\hline Discharged to facility & & & $101(24.0)$ \\
\hline
\end{tabular}

Values are presented as mean \pm standard deviation or number (\%).

COVID-19: coronavirus disease 2019; ICU: intensive care unit; HTN: hypertension; CKD: chronic kidney disease; COPD: chronic obstructive pulmonary disease; NRB: non-rebreather; HFNC: high-flow nasal cannula; NIPPV: non-invasive positive pressure ventilation.

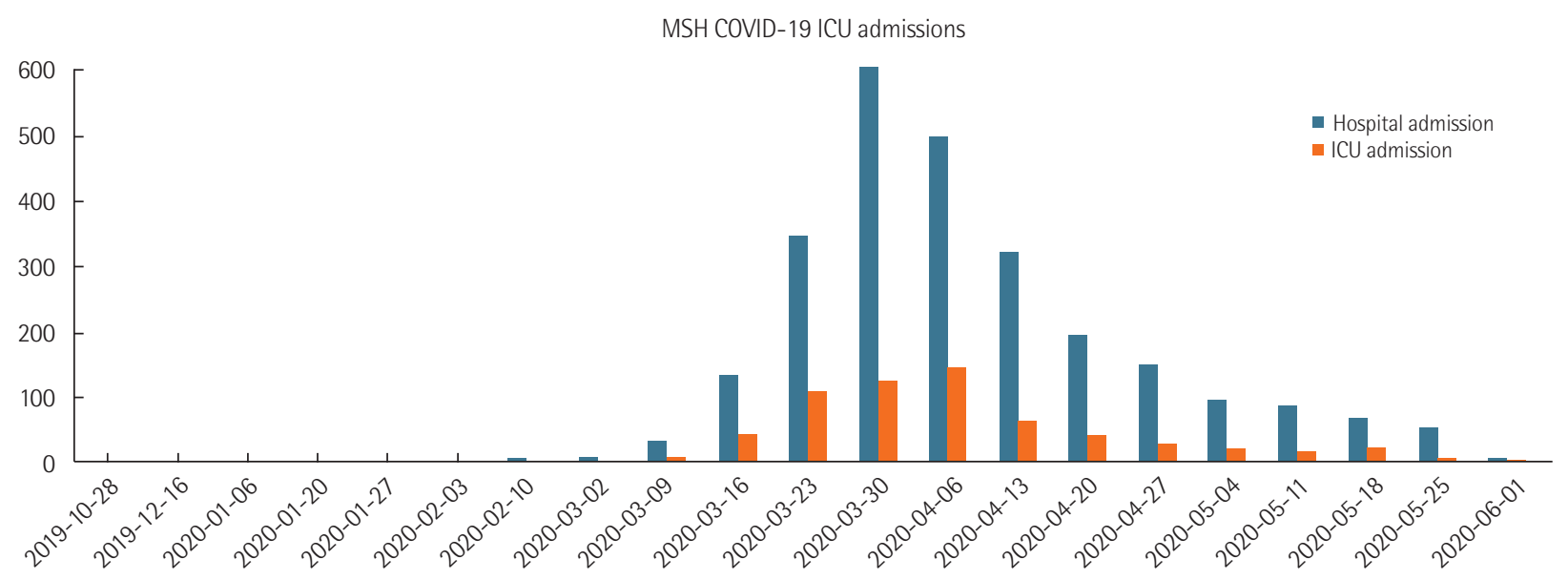

Figure 1. Mount Sinai Hospital (MSH) coronavirus disease 2019 (COVID-19) intensive care unit (ICU) versus hospital admissions. 
Table 3. Clinical outcomes of COVID-19 patients admitted to Mount Sinai Hospital based on age

\begin{tabular}{|c|c|c|c|c|c|c|c|c|c|}
\hline \multirow[b]{2}{*}{ Age (yr) } & \multicolumn{5}{|c|}{ All patients $(n=2,161)$} & \multicolumn{4}{|c|}{ Ever ICU patients $(n=614)$} \\
\hline & $n$ & $\begin{array}{l}\text { Admitted to } \\
\text { ICU }\end{array}$ & Intubated & Died & Discharged & $n$ & Intubated & Died $(\%)$ & Discharged \\
\hline $18-20$ & 12 & $6(50)$ & 0 & 0 & $12(100.0)$ & 6 & 0 & 0 & $6(100)$ \\
\hline $20-30$ & 131 & 18 (13.7) & 5 (3.82) & $2(1.5)$ & $127(96.9)$ & 18 & $5(27.8)$ & $2(11.1)$ & 16 (88.9) \\
\hline $30-40$ & 255 & $53(20.8)$ & $30(11.8)$ & $8(3.1)$ & $240(94.1)$ & 53 & $30(56.6)$ & $8(15.1)$ & $43(81.1)$ \\
\hline $40-50$ & 266 & $68(25.6)$ & $44(16.5)$ & $25(9.4)$ & $232(87.2)$ & 68 & $44(64.7)$ & $21(30.9)$ & $45(66.2)$ \\
\hline $50-60$ & 486 & $121(24.9)$ & $84(17.3)$ & $66(13.6)$ & $402(82.7)$ & 121 & $84(69.4)$ & $45(37.2)$ & $73(60.3)$ \\
\hline $60-70$ & 645 & $180(27.9)$ & $144(22.3)$ & $144(22.3)$ & $491(76.1)$ & 180 & $144(80)$ & $96(53.3)$ & $82(45.6)$ \\
\hline $70-80$ & 658 & $117(25)$ & $87(18.6)$ & $115(24.6)$ & $348(74.4)$ & 117 & $87(74.4)$ & $66(56.4)$ & $49(41.9)$ \\
\hline$>80$ & 328 & 51 (15.5) & 26 (7.93) & $125(38.1)$ & $199(60.7)$ & 51 & $26(51)$ & $25(49.0)$ & $25(49.0)$ \\
\hline
\end{tabular}

Values are presented as number $(\%)$.

COVID-19: coronavirus disease 2019; ICU: intensive care unit.

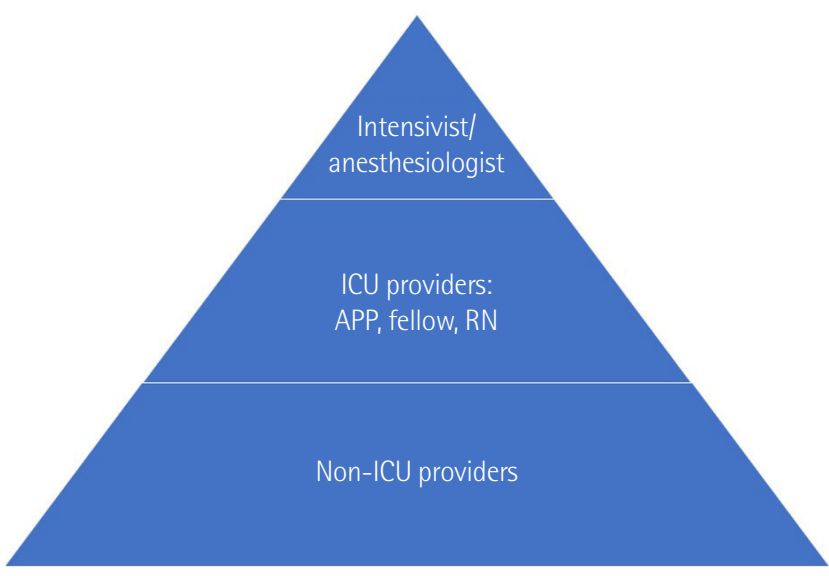

Figure 2. Force multiplier pyramid: a schema for critical care personnel expansion. ICU: intensive care unit; APP: advanced care practitioner; RN: registered nurse.

\section{DISCUSSION}

The 2015 American Hospital Association report estimated that more than 28,800 intensivists delivered ICU care in the US. COVID-19 created a surge in critically ill patients, resulting in hospitals searching for additional staff $[2,3]$. When the MSH ICU capacity was increased from 7 to 11 adult ICUs, $1-2$ attendings, 1-2 advanced care practitioners (APPs), 1-2 fellows, and 1-2 residents per 12-hour shift with 24/7 in house intensivist coverage were on duty $[4,5]$. At least one of the two attendings in each ICU was an adult intensivist, the other was from anesthesiology, surgery, cardiothoracic surgery, neurosurgery, neurology, pediatric ICU, or neonatal ICU. Figure 2 shows the force multiplier pyramid and Table 4 shows the staff deployed to COVID ICUs. Staff shortages were addressed by
Table 4. Staff deployed to COVID ICUs

\begin{tabular}{|c|c|c|}
\hline Fellow & Resident & APP \\
\hline Critical care & Anesthesiology & $\begin{array}{c}\text { General surgery \& sur } \\
\text { gical subspecialties }\end{array}$ \\
\hline $\begin{array}{l}\text { Pulmonary critical } \\
\text { care }\end{array}$ & $\begin{array}{l}\text { Surgery \& surgical } \\
\text { subspecialties }\end{array}$ & Emergency \\
\hline Neurocritical care & $\begin{array}{l}\text { Interventional } \\
\text { radiology }\end{array}$ & $\begin{array}{l}\text { APPs from outside } \\
\text { MSHS }\end{array}$ \\
\hline $\begin{array}{l}\text { Cardiology \& cardiology } \\
\text { subspecialties }\end{array}$ & Medicine & \\
\hline Pediatric subspecialties & Pediatrics & \\
\hline
\end{tabular}

COVID: coronavirus disease; ICU: intensive care unit; APP: advanced care practitioner; MSHS: Mount Sinai Health System.

employing tiered staffing models and training staff from noncritical care areas to serve in critical care areas under intensivist supervision. Travel nurses helped supplement staffing in all ICUs. Equipment such as ventilators, medication, and tube feeding pumps were deployed based on need [6,7].

During the COVID-19 surge, the ICU bed capacity was doubled from 104 to 208. All seven adult ICUs became COVID-19 ICUs. All ICU rooms were converted to negative pressure rooms with HEPA (high efficiency particulate air) filters with outside exhaust and redesigned to accommodate up to two patients. Two ICUs were changed to post-anesthesia care units (PACUs), designated as COVID-19-negative, and were staffed by PACU anesthesiologists, pain management fellows, and intensivists (Table 1). A space formerly used as an ICU reopened as a COVID-19-negative neuroscience ICU and was staffed by neurosurgeons, intensivists, neurologists, and neurosurgery residents. Two medical/surgery units were repurposed as COVID-19-positive ICUs. This unit utilized anesthesia machines as 
ventilators due to ventilator shortage and was co-managed by anesthesiologists and intensivists (Supplementary Material $1)$.

Establishing a new ICU usually requires years of planning, development, investment, and training. This is the first report of creating a de novo anesthesiology-run ICU within days. A location that already had a supply of medical gas, waste pipelines, and an uninterrupted power source was chosen. A telemetry unit was converted to an ICU because it had network interface and a central monitoring station that allowed for remote vital sign monitoring; alarm notification for patient decompensation; and vitals, medication records, and ventilator settings that integrated with the electronic health records. Details of how a stepdown unit was converted into an anesthesia-led critical care unit are described in Supplementary Material 1.

The greatest challenge in converting medical/surgical stepdown beds into ICUs was lack of patient visibility. Doors were kept closed to maintain negative pressure and minimize viral spread. Although windows were added to the doors, patient visibility was inadequate. Audio and visual equipment with a staffed monitoring station were added to many rooms. Tablets allowing video conferencing were attached to walls and focused on both the patient and vital sign monitors to allow audiovisual "spot checks." Communicating critical information and calling for help from behind closed doors necessitated a hands-free device compatible with personal protective equipment (PPE). Nursing staff was familiar with Vocera (Vocera, San Jose, CA, USA), so the system was expanded to include physicians. Low-tech solutions such as whiteboards and dry erase markers allowed writing of critical information on windows. Early in the pandemic, resources were limited, and webcams were not available; however, webcams were eventually installed in COVID-19 patient rooms and proved extremely helpful to monitor patients.

The most important part of the de novo anesthesiology-run ICU was building a team of individuals from different departments with various levels of training. Nurses assigned to this unit were from a medical/surgical floor and were not trained in critical care. One ICU nurse per shift was assigned as an educator [4]. A de-emphasis on title and role was paramount for seamless teamwork and reduced unnecessary exposure and PPE use. Anesthesiology and nursing collaborated to minimize multiple room entries by pairing one person entering and calling out information or needed equipment to a teammate outside who would record information or gather supplies. Intravenous infusion pumps with extra-long tubing were used for access to each room.

MSH has an intensivist-led central venous access service that facilitates tunneled and non-tunneled central venous catheter placement. This service was expanded with the addition of two cardiothoracic anesthesiologists who were deployed to free intensivists to focus on patient care. Dedicated proning teams were created for acute respiratory distress syndrome (ARDS) patients (a team comprised of surgical technicians who were available because elective procedures were suspended). This was overseen by a designated team within ICCM and deployed via Vocera and available 24/7 [8,9]. All ICCM faculty, house staff, and nurses were instructed on safe proning practices including simulation sessions.

Palliative care physicians were placed in all COVID-19 ICUs to assist with family meetings and discussions regarding care goals. Social workers facilitated family meetings via video conferencing. Tablets were placed in each ICU room to facilitate video communication between medical teams, families, and patients. ICCM RRT respond to decompensating patients in the hospital. Normally, this team includes an intensivist, critical care fellow, nurse practitioner, and respiratory therapist. During the COVID-19 outbreak, the team expanded to include two certified registered nurse anesthetist during the day and an interventional radiology or anesthesiology resident at night. CRNAs and APPs from outside institutions provided additional help.

Staff deployed to COVID-19 ICUs were required to perform new roles and learn new processes at an unprecedented speed. The ability to rapidly train and orient staff from a variety of backgrounds, disciplines, and from within and outside MSH posed a significant challenge $[10,11]$. To address this, a training and reference manual, the ICCM handbook, was created. The target audience was medical staff outside critical care (internal medicine, surgery, anesthesiology, interventional radiology, and pediatrics) [12] who had volunteered for COVID duty.

The handbook provided a simple yet comprehensive guide to: (1) complement COVID-19 educational training [13], (2) review before deployment to COVID-19 ICUs, (3) provide justin-time training, and (4) serve as a simple reference for experienced providers. No precedent existed at the time of handbook preparation; thus, initial topics were based on review of existing protocols from institutions in Italy and US, and from references from prior respiratory viral pandemics (including MERS, SARS, and influenza) [14]. Topics included staff safety, PPE use, patient transport, sample collection, pharmacologic treatment, airway management and resuscitation, protocol 
for extended PPE use, ARDS management, and daily workflow in COVID-19 ICUs.

The handbook consisted of a table of contents, a three-page summary for quick reference, and an appendix with protocols (Supplementary Material 2). Protocols were based on state, critical care society, and system guidelines and were structured with illustrations and step-by-step instructions. Sample collection and PPE donning/doffing instructions included illustrations from the centers for disease control and prevention, and intubation and cardiac arrest protocols included a list of needed supplies. The handbook was circulated via the publicly accessible MSHS COVID-19 staff resource website [15].

The first week of the COVID-19 crisis in NYC made it evident that institutional guidelines for intubation of COVID-19-positive patients were needed to ensure maximum frontline worker safety. Prior to crisis onset, ICCM developed a DART including critical care, emergency, anesthesiology, and otolaryngology. Each member reviewed literature $[16,17]$ and guidelines released by the Society for Critical Care Medicine and the Anesthesia Patient Safety Foundation $[12,18]$ to develop COVID19-specific airway management guidelines.

DART addressed anticipated ventilator shortages [19] and safety of noninvasive ventilatory strategies. While delaying intubation could increase the risk of acute catastrophic decompensation and respiratory arrest, controversy remained over the extent of increased viral aerosolization [20,21]. Airway management dictates preparation for intubation as well as multiple backup plans for unanticipated difficulties [22]. "Go bags" were organized for intubation to minimize supply contamination and waste. Anticipated difficult intubations included larger "go bags" with additional supplies.

Many professional society guidelines have the most experienced person perform laryngoscopy for COVID-19 intubations $[12,18,23]$. Our guidelines recommended that COVID-19 intubations be performed by two experienced operators, one for laryngoscopy and the other to assist. COVID-19 intubation teams included intensivists, anesthesiology attendings, anesthesiology senior residents, and nurse anesthetists. DART activations, available for backup at MSH 24/7, assembled critical care, anesthesiology, and otolaryngology physicians for difficult intubations. COVID-19 DART intubations allowed otolaryngologists into the room only if a surgical airway was needed to limit the number of providers exposed and to preserve PPE. Guideline dissemination occurred via email to all departments who provide airway management and through virtual departmental conferences and grand rounds. In addition, high-fi- delity simulation sessions were offered in small groups to all airway providers across departments followed by debriefing to evaluate and reinforce adherence to protocols. MSHS COVID-19 intubation guidelines, updated as of April 16, 2020, are included in Supplementary Material 2.

MSH responded to the COVID-19 surge by quickly expanding critical care bed capacity from 104 to over 200 ICU beds. Teamwork across multiple disciplines and guidelines for airway management, cardiac arrest, anticoagulation, vascular access, and proning was critical to hospital success. Non-ICU staff were used to help reinforce the ICU staff and open additional ICUs.

\section{CONFLICT OF INTEREST}

No potential conflict of interest relevant to this article was reported.

\section{ORCID}

Evan Leibner https://orcid.org/0000-0002-0490-1389

Neha Dangayach https://orcid.org/0000-0002-6485-350X

Umesh Gidwani https://orcid.org/0000-0002-8631-2819

Andrew Leibowitz https://orcid.org/0000-0003-0667-8421

Roopa Kohli-Seth https://orcid.org/0000-0002-6082-1359

\section{AUTHOR CONTRIBUTIONS}

Conceptualization: JW, EL, JH (Joshua Hamburger), SA, JH (Jean Hsieh). Data curation: EL, PT. Formal analysis: EL, JW. Methodology: JH (Joshua Hamburger), JH (Jean Hsieh). Project administration: RKS, AL, UG. Visualization: RKS, AL. Writing-original draft: JW, EL, JH, SA, JH, JH. Writing-review \& editing: ND, UG.

\section{SUPPLEMENTARY MATERIALS}

Supplementary materials can be found via https://doi.org/ 10.4266/acc.2021.00402.

\section{REFERENCES}

1. Johns Hopkins University. Covid-19 dashboard by the center for systems [Internet]. Baltimore (MD): Johns Hopkins University; 2020 [cited 2020 Apr 17]. Available from: https://www. covidtracker.com/. 
2. Halpern NA, Pastores SM. Critical care medicine beds, use, occupancy, and costs in the United States: a methodological review. Crit Care Med 2015;43:2452-9.

3. Halpern NA, Tan KS, DeWitt M, Pastores SM. Intensivists in U.S. acute care hospitals. Crit Care Med 2019;47:517-25.

4. Halpern NA, Tan KS. United States resource availability for COVID-19 [Internet]. Mount Prospect (IL): Society of Critical Care Medicine; 2020 [cited 2020 Apr 17]. Available from: https: //sccm.org/getattachment/Blog/March-2020/United-StatesResource-Availability-for-COVID-19/United-States-ResourceAvailability-for-COVID-19.pdf?lang=en-US.

5. Kumaraiah D, Yip N, Ivascu N, Hill L. Innovative ICU physician care models: Covid-19 pandemic at NewYork-Presbyterian. NEJM Catal Innov Care Deliv 2020;1.

6. Farmer JC, Wax RS, MD, Baldisseri MR. Preparing your ICU for disaster response [Internet]. Mount Prospect (IL): Society of Critical Care Medicine; 2020 [cited 2020 Apr 17]. Available from: https://www.sccm.org/getattachment/Disaster/PreparingforDisasterResponse.pdf?lang=en-US.

7. Halpern NA, Kaplan LJ, Rausen,M, Yang JJ. Configuring ICUs in the COVID-19 Era. Mount Prospect (IL): Society of Critical Care Medicine; 2020.

8. Scholten EL, Beitler JR, Prisk GK, Malhotra A. Treatment of ARDS with prone positioning. Chest 2017;151:215-24.

9. Cherian SV, Kumar A, Akasapu K, Ashton RW, Aparnath M, Malhotra A. Salvage therapies for refractory hypoxemia in ARDS. Respir Med 2018;141:150-8.

10. Kumar P, Kattan O, Broome B, Singhal S. Reassessing Covid-19 needs: how providers can reexamine their surge capacity, supply availability, workforce readiness, and financial resiliency. NEJM Catal Innov Care Deliv 2020;1.

11. Kim MK, Rabinowitz LG, Nagula S, Dunn A, Chalil J, Tao Xu, et al. A primer for clinician deployment to the medicine floors from an epicenter of Covid-19. NEJM Catal Innov Care Deliv 2020;1.

12. Alhazzani W, Møller MH, Arabi YM, Loeb M, Gong MN, Fan E, et al. Surviving Sepsis Campaign: guidelines on the management of critically ill adults with coronavirus disease 2019 (COVID-19). Intensive Care Med 2020;46:854-87.

13. Evan S, Leibner M, Elvera L, Baron M, Ronak S, Shah M, et al. Critical care simulation education program during the COVID-19 pandemic. J Patient Saf Forthcoming 2021.

14. Christian MD, Wax R, Lazar N. Critical care during a pandemic: final report of the Ontario health plan for an influenza pan- demic (OHPIP) working group on adult critical care admission, discharge and triage criteria. Toronto, Ontario, Canada: Toronto, Ontario Health System; 2006.

15. Mount Sinai. Faculty and staff education during COVID-19 [Internet]. New York (NY): Mount Sinai; 2020 [cited 2020 May 27]. https://www.mountsinai.org/about/covid19/staff-resources/critical-care-education.

16. Caputo KM, Byrick R, Chapman MG, Orser BJ, Orser BA. Intubation of SARS patients: infection and perspectives of healthcare workers. Can J Anaesth 2006;53:122-9.

17. Peng PW, Ho PL, Hota SS. Outbreak of a new coronavirus: what anaesthetists should know. Br J Anaesth 2020;124:497501.

18. Zucco, Liana, Levy N, Ketchandji D, Aziz M, Ramachandran SK. An Update on the Perioperative Considerations for COVID-19 Severe Acute Respiratory Syndrome Coronavirus-2 (SARS-CoV-2) [Internet]. Rochester (MN): Anesthesia Patient Safety Foundation; 2020 [cited 2021 Aug 24]. Available from: https://www.apsf.org/article/an-update-on-the-perioperative-considerations-for-covid-19-severe-acute-respiratorysyndrome-coronavirus-2-sars-cov-2/.

19. Ranney ML, Griffeth V, Jha AK. Critical supply shortages: the need for ventilators and personal protective equipment during the COVID-19 pandemic. N Engl J Med 2020;382:e41.

20. Respiratory care committee of Chinese Thoracic Society. Expert consensus on preventing nosocomial transmission during respiratory care for critically ill patients infected by 2019 novel coronavirus pneumonia. Zhonghua Jie He Hu Xi Za Zhi 2020;17:E020.

21. Hui DS, Chow BK, Lo T, Tsang OT, Ko FW, Ng SS, et al. Exhaled air dispersion during high-flow nasal cannula therapy versus CPAP via different masks. Eur Respir J 2019;53:1802339.

22. Apfelbaum JL, Hagberg CA, Caplan RA, Blitt CD, Connis RT, Nickinovich DG, et al. Practice guidelines for management of the difficult airway: an updated report by the American Society of Anesthesiologists Task Force on Management of the Difficult Airway. Anesthesiology 2013;118:251-70.

23. Association of Anaesthetists. Anaesthetic management of patients during a COVID-19 outbreak [Internet]. London: Association of Anaesthetists; 2020 [cited 2020 May 27]. Available from: https://anaesthetists.org/Home/Resources-publications/Anaesthetic-Management-of-Patients-During-a-COVID-19-Outbreak. 
Supplementary Material 1. Anesthesiology intensive care unit (ICU) document

\section{Process of establishing an anesthesia led critical care unit}

Goal: rapidly deploy anesthesiology personnel and equipment to create a critical care unit in medical/surgery units with support from ICCM.

\section{Environment}

a. Requirements:

i. Oxygen, air, vacuum wall line setup with splitters if needed

ii. Network jack access

iii. Uninterrupted power supply (red outlets)

iv. Central monitoring station preferred- anesthesia machine vital monitors can be interfaced with telemetry units

b. Recommendations

i. Options to ameliorate partial or no view rooms

1. Punch a window into all of the doors

2. Reverse the direction of the bed so the head of the bed can be seen from the door

3. Position anesthesia machine so the articulating arm with the vital sign monitor can either face the door/window or AV system

4. Whiteboard installed on door to record personnel names as well as current ventilator settings

\section{AV hookup}

a. Centrally monitored AV system- preferred- 9 AV tower units per monitoring booth with someone stationed who can monitor all 9 patients and report immediately.

b. Tablet/zoom setup- secure camera/tablet to wall facing both patient and monitors. Can only be dialed in to from a second tablet allowing only for spot checks and not continuous monitoring.

6. Communication system- Vocera.

a. Critical to supply units to all staff members including physicians

b. Must develop unique call signs with hierarchy and emergency broadcast function (see appendix)

c. Allows communication through closed doors while wearing PPE to communicate and record vital signs, ventilator settings, supply needs or broadcast for emergency assistance when no one can see or hear you.

\section{Staffing}

a. In house attending physician support recommended given unique environment and machinery with need for rapid problem solving.

b. Consider dynamic staffing model to spread resources between many new units in order to maintain flexibility and reduce number of staff needed to cover each unit

i. Surge system: a backup process to call in order to have more staff immediately available if unit gets very busy with concurrent admission or emergencies.

1. Surge pager: 3,908 or 3,910 - daytime covered by cardiac anesthesiology attending. Evening weekends covered by CT anesthesia fellow in house

2. NICS ICU faculty (Amion): nights

3. CTICU critical care anesthesiologist or surgeon (in house)

4. Backup call attending (24/7 backup coverage scheduled in case of emergency or illness that would not interfere with other clinical duties)- last resort as home call

\section{ii. Secondary resources}

1. Prone team

2. Line service 
3. Palliative care team

4. SW or case manager for identifying NOK and placement if needed

5. Walking rounds with ICCM and or anesthesiology leadership

\section{Supplies}

a. Anesthesia machine- deployed and interfaced by anesthesiology department

i. Equipment:

1. Circuits

2. HEPA or B/V filters- one placed in expiratory limb, 2nd placed at circuit Y

3. HME humidifying filter with gas analyzer sampling line

4. D-fend cartridges

5. $\mathrm{CO}_{2}$ absorbers

6. Spirometry tubing (allows for plateau pressure measurement)

7. ECG, NIBP, SP2 and invasive monitoring cables

8. $25 \mathrm{ft}$ network cables for each room. One waterproof/washable keyboard for machine/network interface management

b. Workroom:

i. Med/surg floors do not have critical care equipment. Goal is to utilize equipment familiar to anesthesiologists to improve workflow.

ii. Create a supply area with stock assessment and refill workflow. Anesthesiology equipment managers and techs may help with this process.

iii. Create packs or "go bags" with supplies for specific tasks (e.g., airway pack, central line pack, arterial line pack.) Goal of "go bags" are to provide critical equipment rapidly without creating waste by bringing too much equipment into a room even during an emergency (see appendix for content)

iv. Stockroom area should be outside of COVID care area to reduce contamination and protect those who take inventory and stock.

1. Stocked and locked anesthesia cart is quickest simplest solution as familiar to anesthesia team and techs who restock.

2. 2 ultrasound machines, 1 video laryngoscope

3. Airway packs with intubation equipment (see airway section)

4. Invasive monitoring and central access packs and extra supplies

5. Sterile gloves

6. Airway supply cart with equipment needed to maintain anesthesia machines and circuits (list above)

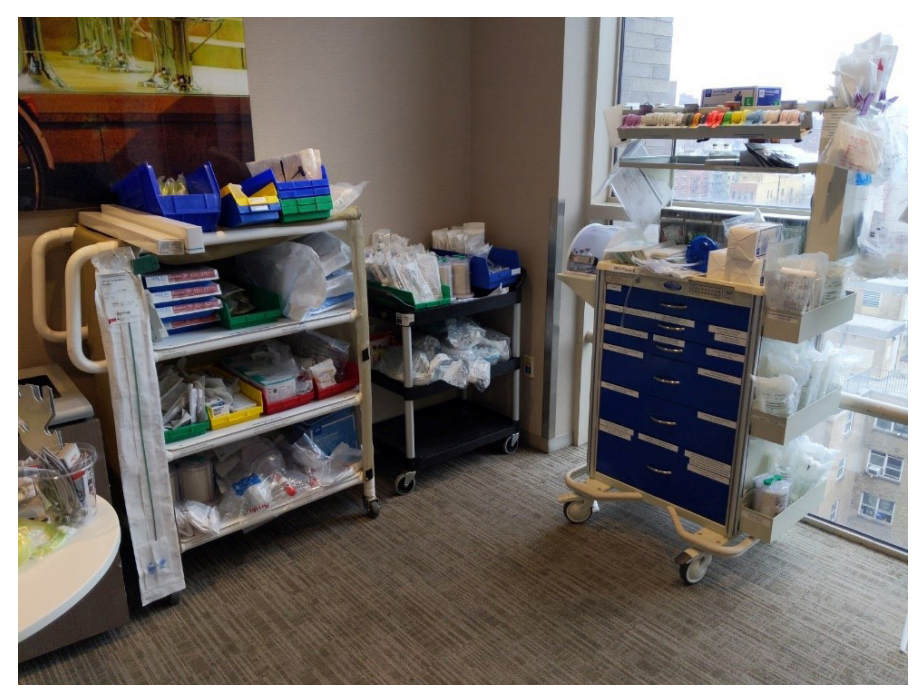




\section{Setup}

a. Circuit order

i. Circuit - > BV filter - > HME filter - > in line suction elbow - > ETT or mask

ii. Must have BV filter proximal to $\mathrm{HME}$ in order to prevent moisture buildup in BV filter. Sampling line for $\mathrm{ETCO}_{2}$ goes to waste gas line and does not contaminate environment

b. Self-inflating resuscitation bag on machine

c. Rubberized perfusion clamp for ETT clamping for disconnects

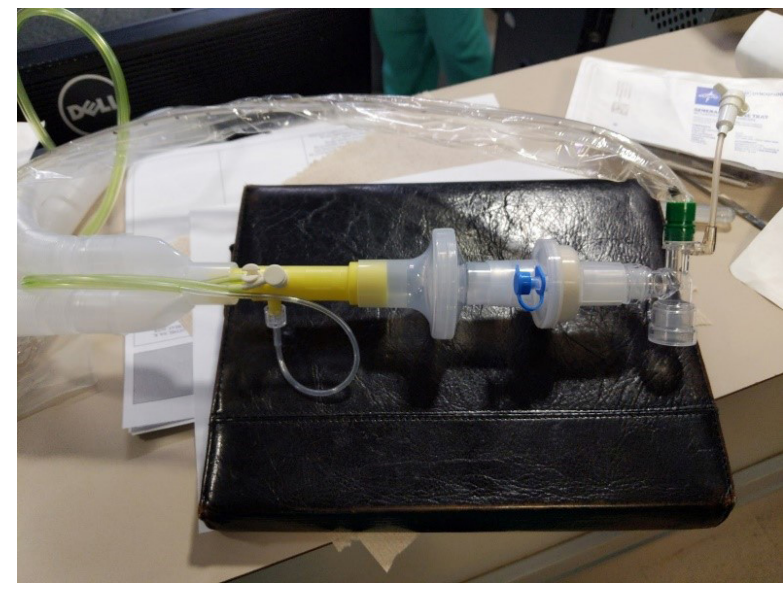

\section{Workflow:}

a. Different from other units given:

i. poor visibility of patients

ii. No respiratory therapy support as they are not familiar with anesthesia machines

iii. $\mathrm{RN}$ colleagues may not have critical care training

b. Add ventilator rounds twice daily as well as extra scheduled patient evaluations

i. Team works in pairs with one person entering room to assess status of circuit, filters, $\mathrm{CO}_{2}$ absorber, change ventilator settings as well as examine patient and environment. 2nd person outside room to pass supplies and record data.

ii. Coordinated with nurses so nursing tasks can be accomplished by anesthesiology team when they enter the room saving PPE and reducing $\mathrm{RN}$ exposure.

c. Ventilator Management (adapted from on American society of Anesthesiology and Anesthesia Patient Safety Foundation recommendations)

i. Power cycle and complete check out prior to connecting. Machine automatically power cycles off after 49 days (GE). Therefore, leave off until connection imminent as to not start the timer.

ii. Initial mode: Pressure control volume guaranteed

iii. May need to increase Pmax to attain TVs.

iv. May need to add air to ETT cuff if Pmax is increased.

v. Flows at $10 \mathrm{~L} / \mathrm{min}$ - goal is to match Flows to MV. Flows > MV leads to poor humidification which can damage lungs. Flow $<$ MV leads to rapid buildup of moisture in the circuit and even the machine that can cause poor filter or machine performance.

vi. Set $\mathrm{FiCO}_{2}$ alarm to $5 \mathrm{~mm}$ and replace $\mathrm{CO}_{2}$ absorber whenever it rises $>3 \mathrm{~mm}$ or majority color changes

vii. Check sampling line D-fend for fluid and replace if needed. Not frequent if setup with spirometry tubing with sampling line proximal to filters.

viii. Measuring plateau pressures: On the ventilator screen- select spirometry, then source and then select patient (instead of machine). Pplat will appear in spirometry section on left side of ventilator monitor. 


\section{Miscellaneous}

a. Creating a team based approach is the most important element in rapidly creating a fully functional intensive care unit in a space not designed for one and with staff who may not be familiar or trained in critical care. This requires constant communication and coordination between physician and nursing leaders as well and as establishing an environment where tasks that are often performed by one type of provider can be done by any person entering a COVID room. Anesthesiologists know how to manage critical care pumps, lines/tubing, patient turning,

b. Education: Daily discussions focusing on teaching non-anesthesiology team members how identify and interpret alarms and setting on anesthesia ventilator.

c. Rapid escalation pathways: what is learned today is implemented tomorrow. All team members must be able to voice ideas or concerns in order to adapt and improve care for patients in a new patient care area. 


\section{Appendix:}

APSF/ASA Guidance on Purposing Anesthesia Machines as ICU Ventilators:

https://www.asahq.org/in-the-spotlight/coronavirus-covid-19-information/purposing-anesthesia-machines-for-ventilators (Please attach included PDF in appendix)

\section{Airway "go bag" contents:}

1.8 .0 and 7.5 endotracheal tube

2. soft stylet

$3.10 \mathrm{ml}$ syringe.

4. Medium sized oral airway

$5.3 \times 10 \mathrm{ml}$ syringe, labeled Rocuronium, Etomidate and Succinylcholine

6. $1 \times 20 \mathrm{ml}$ syringe labeled propofol

7. 1 HME filter

8. 1 orogastric tube

9. 3 lube packets

10. 1 pair of eye protector sticker

11. 1 McGrath size 3 blade

\section{Central line "go bag" contents:}

1. 7 fr triple lumen kit

2. 1 surgical gown

3. 1 sterile ultrasound probe cover with lubricant

4. 1 Biopatch (if CHG Tegaderm not available)

5. 1 CHG Tegaderm or standard Tegaderm dressing

6. 3 Luer-lock adapters

7. 1 sterile 24 inch arterial line tube (for manometry)

\section{Arterial line "go bag" contents:}

$1.20 \mathrm{~g} 12 \mathrm{~cm}$ arterial line kit

2. 1 sterile ultrasound probe cover with lubricant

3. 1 Biopatch (if CHG Tegaderm not available)

4. 1 CHG Tegaderm or standard Tegaderm dressing

5. 1 armboard

6. 2 rolls of 1 inch tape

7. 1 heparinized ABG syringe

\section{Example Vocera call infrastructure:}

Designations (nickname)

1. 7 east anesthesia resident 1-4 (7E residents 1-4)

2. 7 east anesthesia attending 1-2 (7E attending 1-2)

3. 7 east nurse anesthetist (7E CRNA)

Broadcast designations: may be called by any staff member in case help is needed

1. Broadcast to 7 east anesthesia team - calls all physician team members

2. Broadcast to 7 east emergency - calls all physician team members as well as charge nurse

3. NO PUSH TO TALK given its use as primary communication tool between other staff members 


\section{Institute of Critical Care Medicine Handbook for Management of Critically III COVID-19 Patients}

Last Updated 5/15/20

Please note that we will continuously update this handbook as policies evolve 


\section{PREPARED BY:}

Division of Pulmonary, Critical Care, and Sleep Medicine Jean Hsieh, MD MS

Sam Acquah, MD

Neha Goel, MD

Nina Sung, MD

Glen Chun, MD

Hooman Poor, MD

Department of Emergency Medicine

Evan Leibner, MD PhD

Division of Infectious Diseases

Dhruv Patel, MBBS

Gopi Patel, MD

Sarah Schaeffer, MD

Department of Anesthesiology, Perioperative, and Pain Medicine

Jaime Hyman, MD

Andy Leibowitz, MD

Cardiovascular Institute

Anelechi Anyanwu, MD

Umesh Gidwani, MD, MS

Miguel Martillo, MD

Institute of Critical Care Medicine

Roopa Kohli-Seth, MD, Director

With deep gratitude to friends and colleagues too numerous to name, from institutions across the world 


\section{Table of Contents}

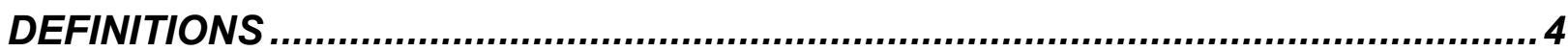

SUMMARY OF CRITICAL CARE MANAGEMENT OF COVID-19 SUSPECTED OR

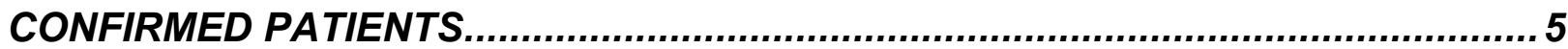

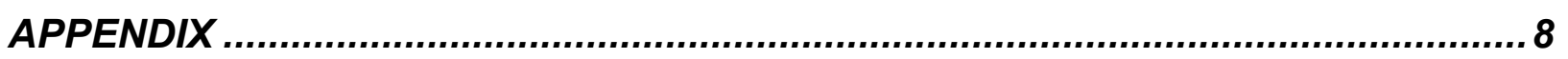

1. HEALTHCARE PROVIDER SAFETY WITH PUI / COVID-19 PATIENTS...............................

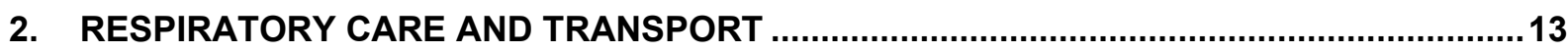

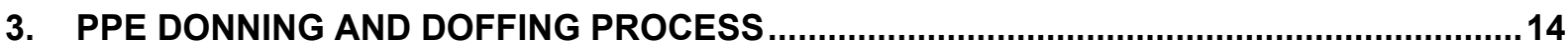

4. SPECIMEN COLLECTION FOR COVID-19 TESTING ....................................................17

5. MSHS TREATMENT GUIDELINES FOR COVID-19 ...................................................... 18

6. MANAGEMENT OF ACUTE HYPOXEMIC RESPIRATORY FAILURE ON GENERAL

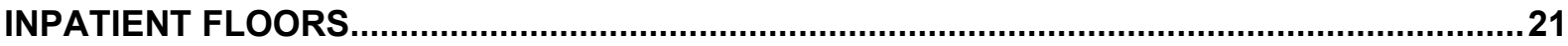

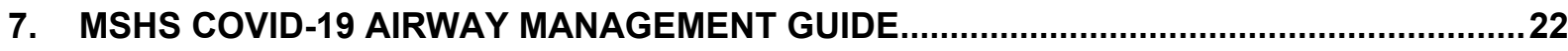

8. VENTILATOR MANAGEMENT OF ARDS IN COVID-19 PATIENTS ..................................24

9. GENERAL MANAGEMENT OF COVID PATIENTS IN THE ICU .........................................26

10. ADULT VV ECMO IN COVID-19 PATIENTS WITH SEVERE ARDS ...................................27

11. PUI / COVID-19 POSITIVE CARDIAC ARREST GUIDE (FOR FLOOR / ICU CODES) ......28 


\section{DEFINITIONS}

\begin{tabular}{|c|c|}
\hline COVID & \\
\hline COVID-19 like illness & $\begin{array}{l}\text { New onset of subjective or measured fever }(\geq 100.4 \mathrm{~F}, 38.0 \mathrm{C}) \underline{\mathrm{OR}} \text { cough } \mathrm{OR} \text { shortness of } \\
\text { breath } \mathrm{OR} \text { sore throat that cannot be attributed to an underlying or previously recognized } \\
\text { condition }\end{array}$ \\
\hline $\begin{array}{l}\text { Patient Under } \\
\text { Investigation (PUI) } \\
\text { (aka Suspected COVID- } \\
\text { 19) }\end{array}$ & Person with COVID-19 like illness, COVID-19 test pending \\
\hline Confirmed COVID-19 & Person with COVID-19 like illness and a positive laboratory test \\
\hline \multicolumn{2}{|l|}{ PROVIDER SAFETY } \\
\hline Limited reuse of PPE & $\begin{array}{l}\text { Using the same N95 respirators for multiple encounters with patients, but doffing after each } \\
\text { encounter. The respirator is stored in between encounters and is donned prior to the next } \\
\text { encounter with a patient }\end{array}$ \\
\hline Extended use of PPE & $\begin{array}{l}\text { Wearing the same N95 respirators for repeated close contact encounters with several } \\
\text { different patients, without removing between patient encounters }\end{array}$ \\
\hline $\begin{array}{l}\text { PPE reprocessing } \\
\text { program }\end{array}$ & Sterilizes N95 that are not misshapen, heavily soiled or wet \\
\hline \multicolumn{2}{|l|}{ PUBLIC SAFETY } \\
\hline Isolation & "separation of sick people with a contagious disease from people who are not sick" \\
\hline Quarantine & $\begin{array}{l}\text { "separation of asymptomatic people who were exposed to a contagious disease to see if } \\
\text { they become sick" }\end{array}$ \\
\hline Social distancing & "stay at home to the extent possible and only leave home for essential tasks" \\
\hline
\end{tabular}

MSHS COVID-19 PPE Practices 3/25/20 MSHS PPE workflow for Endemic Units with Aerosolizing Procedures 3/25/20 NYC DOH Health Alert 


\section{SUMMARY OF CRITICAL CARE MANAGEMENT OF COVID-19 SUSPECTED OR CONFIRMED PATIENTS}

Level of Care:

- Patients with confirmed COVID and rapidly increasing $\mathrm{O} 2$ requirements should be closely monitored and considered for transfer to ICU level of care

Staffing:

- Minimize number of clinical staff who enter patient room

- Medical students are not permitted to participate in the clinical care of COVID patients

PPE (PUI \& COVID-19 positive):

- Encouraged practices

- DO CONSERVE:

- N95: extended use / limited reuse; face shield: reuse; N95 : reprocessing program

- DON'T: wear gown/gloves at workstation or when not working with patients

- Surgical facemask in all common areas

- In patient room: surgical facemask ${ }^{1}$, face shield, isolation gown, gloves

- $\quad \mathbf{N 9 5}$ (instead of surgical facemask) is used for (1) aerosol-generating procedures (e.g., intubations, cardiac arrest, chest physiotherapy) and (2) in rooms with PUI/COVID+ patients on HFNC/bipap

- Isolation gown: offers full protection against droplets; the same gown can be worn when interacting with COVID19 patients in an isolation cohort (discard if visibly ripped or soiled)

- Gloves: change between every patient encounter (mask and face shield change between patients NOT required)

Hand Hygiene

- must be performed to prevent transmission; sanitizer or soap and water are acceptable

Patient Room:

- Isolation designation: Special Droplet + Contact precautions

- If requiring frequent aerosolized procedures (e.g., HFNC, bipap, trach collar), will need negative pressure room

- Cohorting is allowed for COVID-19 positive patients. Cohorting is NOT allowed for PUI (must be single room)

Patient Visitors:

- No visitors

- Encourage patients to communicate with family / friends using available smart tablets

Patient Transport:

- Necessity should be confirmed by MD prior to transport

- Non-intubated patients: wear a facemask, nasal cannula under facemask, or nonrebreather during transport

- Intubated patients and patients on bipap should be transported on the ventilator with HEPA filter (no BMV)

- Staff transporting patient should wear a surgical mask

- The receiving department should be informed that enhanced droplet and contact precautions are required

Mobility:

- Standard care. No ambulation outside room.

Personal clothing \& Equipment:

- Use ONLY disposable stethoscopes

- Clean personal devices (phone, pager, etc) frequently with rubbing alcohol

\section{LABORATORY TESTING}

- Obtain procalcitonin, d-dimer, fibrinogen, C-reactive protein, $\mathrm{LDH}$, ferritin in addition to routine testing

- A negative result in a symptomatic patient who is not improving and with a high suspicion for COVID-19 may represent a false negative. Consider discussing with Infection Prevention and continuing isolation in meantime

- In critically ill, consider arterial line to aid ABGs, blood draws, BP monitoring with less staff exposure

\section{IMAGING}

- Consider utility of bedside and other imaging/diagnostic studies in context of personnel exposure and potential for equipment contamination

- $\quad$ Batch indications for CXR together (i.e., intubation, central line, NGT)

- Consider use of bedside ultrasound for evaluation of lung pathology and assessment for cardiomyopathy

- $\quad$ Limit use of CT scans when possible

\section{RESPIRATORY SUPPORT}

- Limit use of aerosol-generating modalities whenever possible (e.g., sputum induction, nebulized medications) Updated $2 / 22 / 21$ 
- Use MDI instead of nebulized medications

- Supplemental oxygen if SpO2 $<92 \%$

- Nasal cannula and non-rebreather masks may be used as usual

Avoid Venti masks due to risk of aerosolization

A carefully monitored trial of HFNC (if unavailable, BIPAP with filter on exhalation port) is acceptable. Patient needs to be in airborne isolation room and HCP need to use N95 (instead of surgical masks) for PPE

- If BIPAP must be used, use closed circuit ventilator with a filter on exhalation port

\section{INTUBATION:}

- $\quad$ N95 (instead of surgical mask), face shield, double gloves, gown, hat must be used

- Plan for rapid sequence intubation by most experienced physician. Ideally 2 people $(\max 3)$ in room during intubation. (see Intubation Guidelines in APPENDIX for details)

\section{VENTILATOR MANAGEMENT}

- Initiate all patients on low tidal volume ventilation immediately (4-6cc/kg IBW)

- Goal SpO2 no higher than $96 \%$

- Moderate to severe ARDS (P/F<200)

- Use ARDSNet low or high PEEP ladder (goal plateau $<\mathbf{3 0} \mathbf{~ c m ~} \mathbf{H 2 O}$ )

- If ventilator dyssynchrony, sedate to RASS -4/-5

- If persistent ventilator dyssynchrony, persistently high Pplateau, consider neuromuscular blocking agents (bolus preferred over continuous infusion; if no improvement, infusion x 4 - 48hr)

- $\quad$ Severe ARDS (P/F<100)

- Consider early proning and consulting ECMO team (Proning Guidelines forthcoming)

- consider inhaled epoprostenol (prefer over iNO) as a bridge to proning / ECMO

- ECMO team should be consulted if patient is intubated with FiO2 $>\mathbf{9 0 \%}$ with: P/F $<50$ for $>3 \mathrm{~h}$ or $\mathrm{P} / \mathrm{F}<\mathbf{8 0}$ for $>6 h$

\section{OTHER PROCEDURES}

- Consider (1) arterial line to facilitate blood draws and reduce contact time, (2) central line if requiring pressors / difficult veins, (3) NGT at time of intubation to assess placement using same CXR

- Procedures should be performed by an experienced physician in order to minimize clinician time spent in close proximity to patient

- 2 providers ( 2 MDs or MD + RN) should be in the patient's room for the duration of the procedure

- If increased risk of aerosolization, use N95

- Non-disposable equipment (e.g. ultrasound) should be wiped down with green wipes in the room ( $>2 \mathrm{~min}$ contact time). Repeat after exiting room.

- Avoid bronchoscopy unless absolutely necessary (high risk of aerosolization)

\section{HEMODYNAMIC MANAGEMENT}

- Use multimodal assessment strategy (skin temp, capillary refill, lactate) to guide fluid resuscitation

- $\quad$ Conservative fluid strategy, keep net negative, avoid maintenance fluids

- $\quad$ Prefer $\underline{\text { buffered }} \underline{\text { crystalloids }}$ over colloids/unbalanced crystalloids

- Target MAP 60-65 using levophed as first-line agent, and vasopressin if $2^{\text {nd }}$ agent needed

- If shock w/ cardiac dysfunction despite IVF and levophed, add dobutamine

- If refractory shock or chronic steroid use, consider stress dose steroids (hydrocortisone 50mg q6h)

- Be mindful of the potential for development of cardiomyopathy in COVID patients

- Diuresis per FACCT-Lite strategy if off vasopressors $>12$ hours and not clinically hypovolemic

\section{PHARMACOLOGIC TREATMENT (see TREATMENT guidelines in APPENDIX)}

- Acetaminophen for fever (no clear evidence that ibuprofen can make COVID-19 worse, can avoid if concerned)

- Bacterial co-infection may occur, and treatment of bacterial pneumonia (CAP or HCAP as appropriate) should be initiated upon initial presentation. Consider stopping antibiotics after 48-72 hours if micro data is negative, there is no neutrophilia / bandemia, purulent sputum or lobar infiltrate

- Viral co-infection is rare, but may occur. If a patient tests positive for an additional respiratory viruses, the result should not be presumed to be false positives.

- Nebulized medications must be avoided whenever possible; use MDI instead

- Steroids can be used for refractory shock, COPD/asthma exacerbation

- Severe disease +/- other end organ damage: bilateral pneumonia plus intubated or NRB / HFNC / BIPAP 
- Consider: convalescent plasma, Remdesivir EUA, Mesenchymal stem cells (MSH only)

- If no end organ damage and intubated $\leq 48$ hours: Tocilizumab (IL6-receptor monoclonal antibody)

- Clinical trials: Remdesivir, Gimsilumab (anti-GM-CSF)

\section{CARDIAC ARREST}

- Don PPE before entering room - N95, eye protection, hat, gown, double gloves; room door remains closed

- Use automated external compression device (LUCAS) if available

- If patient already intubated: perform CPR on VC mode, FiO2 $100 \%$

- Hold compressions during intubation to minimize aerosolization 


\section{APPENDIX}

\section{HEALTHCARE PROVIDER SAFETY WITH PUI / COVID-19 PATIENTS}

For current information on MSHS PPE Guidelines and Directory https://www.mountsinai.org/about/covid19/staff-resources/ppe-directory-guidelines "PPE Practices" file includes

- Criteria to discontinue Special Droplet and Contact Precautions for COVID-19

- PPE recommendations (N95 respirator, gown, eye protection)

- Process for extended use / reuse of N95 respirators and face shields

- Prevention of skin breakdown with extended use of N95 respirators

For current information on types of approved PPE:

https://www.mountsinai.org/files/MSHealth/Assets/HS/About/Coronavirus/PPE_Directory.pdf

\section{For current information on the Extended Use/Reuse}

https://www.mountsinai.org/files/MSHealth/Assets/HS/About/Coronavirus/Process-for-the-LimitedReuse-and-Extended-Use-of-N95s-and-Face-Shields-v2.pdf

For the current Staff Masking Policy:

https://www.mountsinai.org/files/MSHealth/Assets/HS/About/Coronavirus/Staff-Masking-Policy.pdf
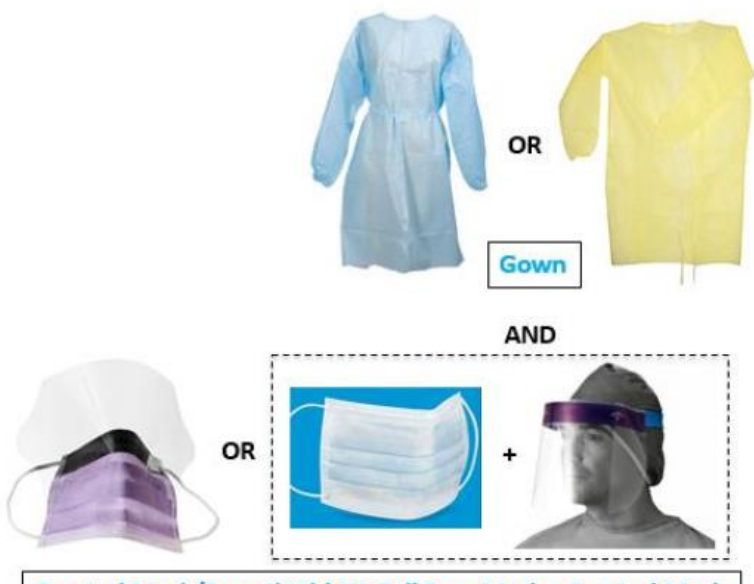

AND

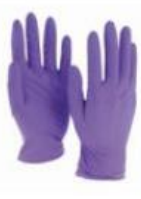

Gloves 


\section{PPE Tips:}

- Minimize the frequency of room entry by consolidating tasks and bringing in all the supplies you need

- Limit number of HCP in room during procedure to those essential for procedure support

- PPE conservation is encouraged: practice extended use and limited reuse for N95, reuse for face shield; reprocessing program for $\mathrm{N} 95$

- For HCP with:

- Glasses - consider eyeglass hooks to prevent them from slipping down

- Long hair - tie hair back, no loose strands, don't tuck hair into collar of yellow gown

- Beards - beard cap or beard trim

\section{Surgical Mask and N95 Respirator Use}

- Surgical mask should be worn when providing routine direct patient care

- If provider has history of high risk exposure to COVID-19, wear surgical mask in common areas unless N95 is indicated

- N95 conservation

- Surgical mask can be worn over an N95 during patient encounters if using goggles; change surgical mask between patients if aerosolizing procedure (not necessary with face shield)

- Wear same N95 for the duration of the shift; only change if soiled or wet; discard @ end day

- At end of shift: if not heavily soiled, wet, misshapen, place in reprocessing box

- Procedures that require N95 to prevent high risk exposure

- BIPAP, CPAP, High Flow Nasal Cannula (HFNC) for duration of therapy

- Intubation

- Chest physiotherapy, nebulizer, suctioning tracheostomy and airway

- Tracheostomy placement

- bronchoscopy, bronchoalveolar lavage

- Sputum induction, endotracheal aspirate collection

\section{Isolation Precautions}

To discontinue Special Droplet and Contact Precautions for inpatient COVID-19 patients, must meet ALL 3

- Afebrile $(<100.0 \mathrm{~F})$ for $\geq 72$ hours without use of antipyretics AND

- Marked improvement in symptoms (e.g. cough, shortness of breath) AND

- At least two consecutive negative PCR for SARS-CoV2 collected $\geq 24$ hours apart 


\section{Personal Protective Equipment (PPE) FAQ During COVID-19}

This document is applicable to all inpatient settings, including the Emergency Department.This information is subject to change based upon updated information

\section{MASKS}

Does a surgical mask provide enough protection for me?

Using a surgical mask is intended to protect staff by reducing the risk of potential exposure. We are concerned about transmission from patients to staff but also between anyone who may be contagious but does not know it (this includes staff, patients and visitors).

How does the Governor's Executive Order on mask use impact me?

The Governor's Executive Order stated that all individuals should use a face mask in public when they are unable to maintain a distance of six feet from other people. MSHS will be providing surgical masks to all staff for compliance with this order. Please speak with your supervisor about obtaining a mask if you have any questions.

When do I wear an $\mathrm{N} 95$ respirator?

N95 respirator with eye protection (attached or separate face shield/goggles) should be worn when performing aerosol-generating procedures for PUI or COVID-19 patients (e.g., tracheal intubation, non-invasive ventilation, tracheostomy, cardiopulmonary resuscitation, bronchoscopy) or by staff working on units/treatment areas where COVID-19 is considered to be endemic with regularly occurring aerosolizing procedures (e.g., ED, ICU, L\&D, OR).

What is MSHS doing to ensure that we have N95 respirators when we need them most? We have been very actively and successfully sourcing N95 respirators for our staff during the COVID-19 pandemic. Adhering to our policy is critically important at this time. We are asking staff to store N95 respirators between patients and use the same N95 respirator for COVID positive patients cohorted in the same room, unit, or area.

\section{EYE PROTECTION}

What should I wearto protect my eyes when with a COVID positive patient or a PUI?

Acceptable eye protection includes full face shield,surgical mask with attached face shield, and goggles.

Are goggles equal to a face shield in terms of protecting my eyes?

Goggles are an equal alternative to a face shield for eye protection as both will protect your eyes from splashes, sprays and droplets.

Can I reuse face shields in between patients with COVID or PUIs?

Similar to N95 respirators, we are asking staff to clean and store face shields between patients. They should be discarded at the end of the shift.

\section{GOWNS}

What gown should I wear for protection when with a COVID positive patient or PUI?

The gowns available at your sites have been evaluated by our infection prevention, life safety, and other clinical experts and validated as safe and effective.

\section{GENERAL PPE}

What about full body suits or "Tyvek" suits? 
Full body suits or "Tyvek" suits are not part of the recommended PPE. They are not articles of clothing and so should not be worn under gowns. Gowns are easier to put on and, in particular, to take off. They are generally more familiar to healthcare workers and hence more likely to be used and removed correctly. Full body suits require a lot of training to avoid contamination during doffing. Any protective barrier PPE worn to care for a COVID-19 positive patient or PUI is considered contaminated. This PPE must be discarded before leaving the contaminated area-the patients' room or the unit if the entire unit is a cohorted COVID unit.

\section{Can I bring my own PPE to wear at work?}

No, staff must wear the PPE that is provided to them to ensure an appropriate level of protection. All PPE used on site at Mount Sinai facilities should come from the Mount Sinai Health System supply chain. 


\section{Extended use and limited reuse of N95 Respirators and Face Shields}

\section{EXTENDED USE}

Extended use refers to the practice of wearing the same N95 respirators for repeated close contact encounters with several different patients, without removing between patient encounters.

Extended use is well suited to situations for cohorted COVID patients whose care requires use of a respirator (e.g., housed on the same hospital unit or same room).

\section{Instructions:}

- The N95 respirator is worn continuously by a provider taking care of multiple patients in a cohort.

- Limited Reuse procedure below applies when patient care is complete or at the end of shift

\section{LIMITED REUSE}

Limited reuse refers to the practice of using the same N95 respirator with multiple patients during one shift. The respirator is stored in between encounters and is donned before the next encounter with a patient. The N95 respirator and face shield are discarded at the end of the shift.

\section{Step-by-Step Instructions:}

After completing care of a known or suspected COVID-19 patient:

\section{While in patient room}

a. Doff all PPE except mask and face shield

b. Perform hand hygiene

2. Exit room while wearing face shield and mask

3. Put on clean gloves

4. Remove face shield from the back of the head

a. Use green wipe (e.g. hydrogen peroxide) to disinfect face shield (wipe inside to outside), allow to dry 2 min

b. Place clean face shield in dedicated paper bag to individual employee and place in designated area or hang on hook outside of patient room

c. To remove residue, use alcohol wipes

5. Remove gloves, hand hygiene, put on clean gloves

6. Remove $\mathbf{N 9 5}$ respirator from back of head

a. Place N95 respirator in dedicated paper bag to that individual employee (and patient where applicable) and place in designated area

7. Discard the N95 respirator and face shield at the end of shift. 


\section{RESPIRATORY CARE AND TRANSPORT}

Tips:

- Caution when using HFNC or BIPAP due to risk of dispersion of aerosolized virus in the health care environment with poorly fitting masks ${ }^{4}$

- Avoid nebulized medications; use MDI instead

- Avoid Venti-mask because of risk of aerosolization

- Staff transporting patient should wear a mask

\begin{tabular}{|c|c|c|c|c|}
\hline \multirow[t]{2}{*}{ Type of Patient } & \multicolumn{2}{|c|}{ In Unit } & \multicolumn{2}{|c|}{ Transport } \\
\hline & Not intubated & Intubated & Not intubated & Intubated \\
\hline $\begin{array}{l}\text { Patient Under } \\
\text { Investigation } \\
\text { (PUI) } \\
\underline{\text { OR }} \\
\text { Confirmed } \\
\text { COVID-19 } \\
\text { positive }\end{array}$ & $\begin{array}{l}\text { Nasal cannula or } \\
\text { nonrebreather } \\
\text { High Flow Nasal } \\
\text { Cannula BIPAP - use } \\
\text { closed circuit ( } 840 \\
\text { vent) with filter on } \\
\text { exhalation port. } \\
\text { Use these with caution } \\
\text { and close monitoring } \\
\text { for decompensation. } \\
\text { Patient needs to be in } \\
\text { negative pressure } \\
\text { room and providers } \\
\text { need to use N95 } \\
\text { masks. }\end{array}$ & $\begin{array}{l}\text { Mechanical ventilator } \\
\text { with filter on exhalation } \\
\text { port }\end{array}$ & $\begin{array}{l}\text { Nasal cannula under } \\
\text { surgical mask or } \\
\text { nonrebreather } \\
\text { If possible, avoid } \\
\text { transporting on HFNC / } \\
\text { BIPAP because of risk } \\
\text { of aerosolization }\end{array}$ & $\begin{array}{l}\text { Portable ventilator with } \\
\text { filter on exhalation port } \\
\text { No BMV }\end{array}$ \\
\hline
\end{tabular}




\section{PPE DONNING AND DOFFING PROCESS}

\section{DONNING PPE}

1. Perform hand hygiene

2. Don yellow gown

Coach makes sure gown covers your back

Tie straps on the side of your body

3. Put on mask*

Do not cross straps

Pinch nose to ensure tight fit

4. Put on eye protection (face shield or goggles)

5. Put on gloves

Make sure thumbs are in gown thumb hole

Gloves over yellow gown so no skin exposed

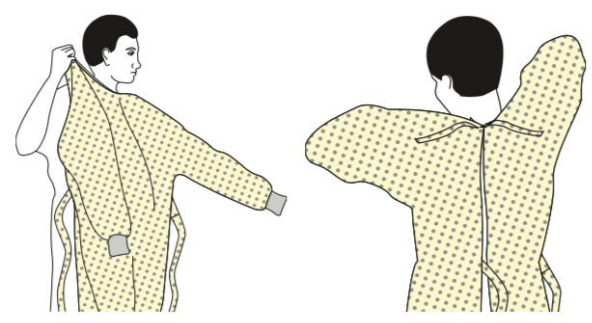

*Use N95 instead of mask for
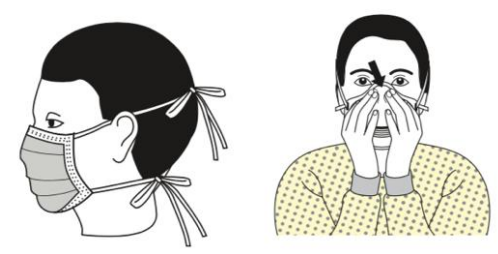

- aerosolizing procedures

- COVID+ or PUI patient on HFNC or BIPAP

- Endemic treatment area with regularly occurring aerosolizing procedures (e.g., ED, ICU, OR, Labor \& Delivery)

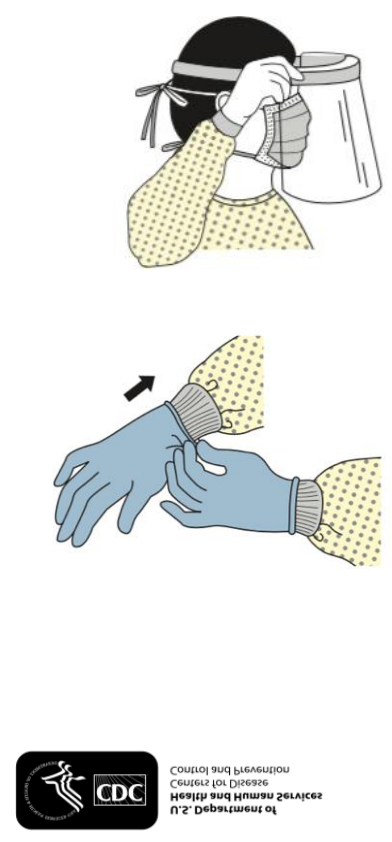

Adapted from instructions by Dr. Sam Acquah, Critical Care 


\section{DOFFING PPE}

Remember front of gown / face shield / mask can be contaminated, so don't touch the front

In endemic treatment areas with regularly occurring aerosolizing procedures (e.g., ED, COVID-only ICU)

- Face shield and N95 do NOT have to be removed between patient encounters unless soiled

- If NOT enclosed treatment area (e.g., ED), doff gown (and gloves) after each patient encounter

- N95 can be worn for the duration of your shift

- Used N95 must be removed with clean hands and can be stored in paper bag until reuse

If ante-room

- doff all PPE in ante-room

If no ante-room

- Doff all PPE except face mask inside room (at least 6 feet away from patient)

- Exit room, perform hand hygiene, then doff face mask and perform hand hygiene again

\section{Glove and Gown Removal}

Method 1 - Gloves, then Gown Removal

1. Remove gloves using non-touch technique

2. Perform hand hygiene

3. Grasp inner neck of gown, break apart

- Pull gown off and away from shoulders

- As you go, turn gown inside-out and roll into inside-out bundle

- discard

4. Perform hand hygiene

5. If any breach is noted, perform hand hygiene immediately.

Method 2 - Simultaneous Gown and Glove Removal

1. Untie gown

- Roll off gown inside out into a bundle, peeling off gloves inside out at the same time

- Bare hands only touch inside of bundle. Discard.

2. Perform hand hygiene

3. If any breach is noted, perform hand hygiene immediately.
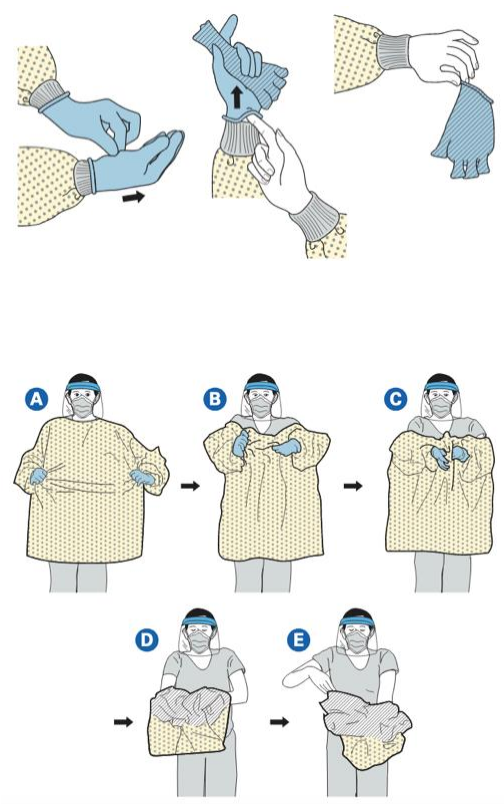


\section{Face Shield Removal}

After aerosolizing procedure, when soiled, or simply need to remove

1. with clean gloves, remove from back of the head

2. use hydrogen peroxide wipe (green canister) to wipe inside $\rightarrow$ outside of face shield. Let sit 1 minute.

3. remove residue with alcohol wipe

4. Place in dedicated paper bag or re-wear

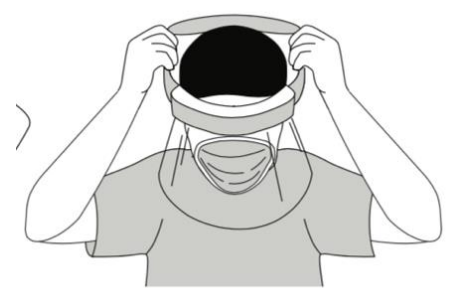

\section{Mask Removal}

1. Remove gloves. Perform hand hygiene

2. Remove from back of your head

3. N95: Leaning forward, first remove bottom strap, then remove top strap and discard or store in paper bag until next use

4. Perform hand hygiene 


\section{SPECIMEN COLLECTION FOR COVID-19 TESTING}

Tips: Your test is only as good as your specimen. Insert NP swab into nostril parallel to the palate. CDC does NOT consider NP swab collection an aerosolizing procedure so N95 not required.

\section{If intubated, endotracheal aspirate (ET) is preferred}

1. Equipment

- 1 x Flocked swab with plastic shaft with tube of Universal Transport Medium (UTM) in same package

- Tongue depressor (optional but helpful)

- Completed Label with: patient's full name, date of birth, date and time of specimen collection, specimen source (OP or endotracheal)

- Biohazard bag for sample

- Bag of ice for sample transport

2. Don PPE and enter patient's room (surgical mask, face shield, gown, gloves)

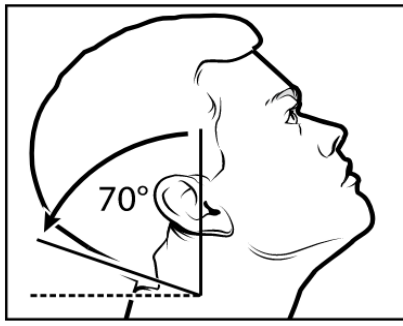

1 Tilt patient's head back 70 degrees.
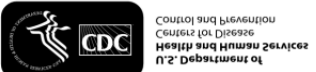

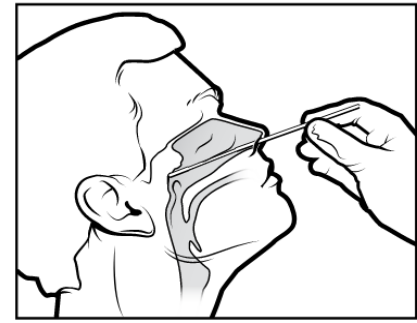

2 Insert swab into nostril. (Swab should reach depth equal to distance from nostrils to outer opening of the ear.) Leave swab in place for several seconds to absorb secretions.

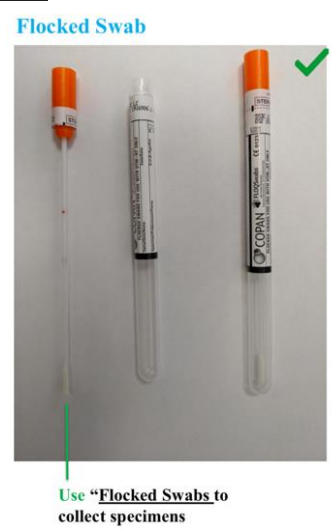

3. Collect specimens

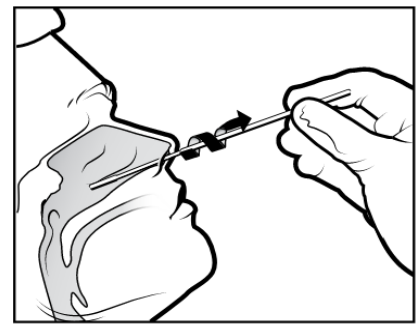

3 Slowly remove swab while rotating it. (Swab both nostrils with same swab.)

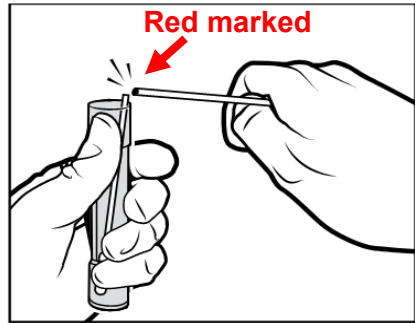

4 Place tip of swab into sterile viral transport media tube and snap/cut off the applicator stick.
a. Nasopharyngeal swab: Estimate distance to insert NP swab by measuring distance from nose to ear. Using same swab, repeat in other nostril.
b. Immediately place swab into tube of UTM, break swab at the red marked line leaving tip in tube.
c. Close and label tube, otherwise lab will reject specimen. Place tube and downtime form in biohazard specimen bag

4. Exit room

5. Place specimen bag inside $\underline{\text { ice }}$ bag and immediately transport to Microbiology Lab 


\section{MSHS TREATMENT GUIDELINES FOR COVID-19}

\begin{tabular}{|c|c|c|}
\hline Sinat Mness Severity ${ }^{1}$ & Current Potential Therapy Options & Notes \\
\hline Asymptomatic & Supportive care & \\
\hline $\begin{array}{l}\text { Symptomatic not requiring } \\
\text { supplemental oxygen (>94\% on } \\
\text { room air) }\end{array}$ & $\begin{array}{l}\text { Supportive care } \\
\text { SARS CoV-2 specific antibody therapy for patients at high risk of progression to } \\
\text { severe COVID-19 }\end{array}$ & $\begin{array}{l}\text { Initiation of either remdesivir or corticosteroids is not recommended. } \\
\text { Emergency use authorization (EUA) monoclonal antibody therapies: } \\
\text { Bamlanivimab } \\
\text { The FDA issued an EUA on November } 9,2020 \text { for bamlanivimab, a } \\
\text { single monoclonal SARS-CoV2 antibody, in select non-hospitalized } \\
\text { patients } 12 \text { years of age or older ( } 240 \mathrm{~kg} \text { ) with a laboratory-confirmed } \\
\text { COVID-19 (i.e., direct SARS-CoV2 viral test), symptom onset within! } \\
\text { days and risk factors for progression to severe COVID-19. } \\
\text { Casirivimab/lmdevimab } \\
\text { The FDA issued an EUA on November } 21,2020 \text { for } \\
\text { casirivimablimdevimab, a dual monoclonal SARS-CoV2 antibody } \\
\text { cocktail, for similar indications as bamlanivimab. }\end{array}$ \\
\hline $\begin{array}{l}\text { Hospitalized requiring low-flow } \\
\text { nasal cannula } \\
\text { (SpO2 } \leq 94 \% \text { on } \mathrm{RA})\end{array}$ & $\begin{array}{l}\text { Supportive care } \\
\text { Consider: } \\
\text { Anticoagulation } \\
\text { Convalescent plasma or SARS-CoV-2 specific antibody therapy }{ }^{3-8 x} \\
\text { In addition to remdesivir, anticoagulation, antibody therapy, and dexamethasone } \\
\text { consider referring for enrollment in available Clinical Trials. } \\
\text { *Not inclusive of EUA bamlanivimab and casirivimab/imdevimab }\end{array}$ & 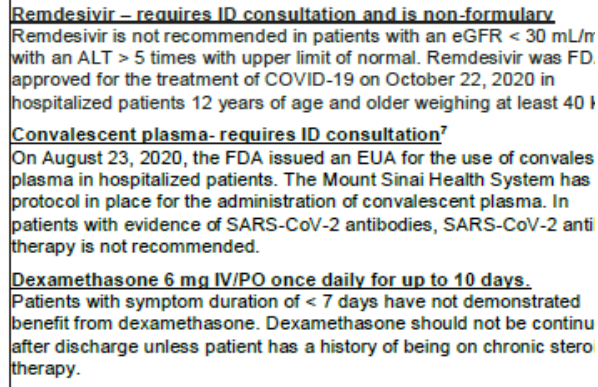 \\
\hline $\begin{array}{l}\text { Hospitalized requiring non- } \\
\text { rebreather, high flow nasal } \\
\text { cannula, or non-invasive } \\
\text { ventilation (i.e., BiPAP) }\end{array}$ & $\begin{array}{l}\text { Supportive care } \\
\text { Recommended: } \\
\text { Anticoagulation } \\
\text { Convalescent plasma or SARS-CoV-2 antibody therapy* } \\
\text { In Rexamethasone } \\
\text { In addition to remdesivir, anticoagulation, antibody therapy, and dexamethasone } \\
\text { consider referring for enrollment in available Clinical Trials. } \\
\text { "Not inclusive of EUA bamlanivimab and casirivimab/imdevimab }\end{array}$ & See above \\
\hline $\begin{array}{l}\text { Hospitalized requiring } \\
\text { mechanical ventilation or ECMO }\end{array}$ & $\begin{array}{l}\text { Supportive care } \\
\text { Consider } \\
\text { Anticoagulation } \\
\text { In addition to anticoagulation and dexamethasone consider referring for enrollment in } \\
\text { available Clinical Trials. }\end{array}$ & $\begin{array}{l}\text { Evaluation for the appropriateness of convalescent plasma will be on } \\
\text { case-by-case basis. Currently, data demonstrating benefit are lackins } \\
\text { these populations. } \\
\text { Remdesivir is not recommended. }\end{array}$ \\
\hline
\end{tabular}

MSHS COVID-19 Treatment Guidance November 30, 2020 


\section{Medications:}

\section{Anticoagulation $^{8,9}$ The Mount Sinai Health System COVID-19 Anticoaqulation Protocol}

Bamlanivimab $^{2,10}$

The FDA issued an emergency use authorization (EUA) for outpatient infusion of bamlanivimab on November 9,2020 . Bamlanivimab is a monoclonal antibody targeting tl Benefit has not been observed in patients who require oxygen or who are hospitalized.

- National allocation of bamlanivimab will be made weekly to states based on reported 7-day hospitalizations. The allocation to MSHS is limited and in order to allow 1 adherence to the EUA the prescribing of bamlanivimab will be adjudicated by a multidisciplinary committee after screening and Infectious Diseases consultation.

- Patients 12 years or older (and over $40 \mathrm{~kg}$ ) referred for bamlanivimab must have a documented direct SARS-CoV2 viral test (antigen or PCR), symptoms of COVID risk for progressing to severe COVID-19. These high-risk conditions are described in the fact sheet for health care providers.

Dosing:

$700 \mathrm{mg}$ IV $\times 1$ dose infused over 1 hour

Caution:

Monitor for infusion reactions and/or anaphylaxis for 1 hour after infusion

- Adverse events should be reported to FDA Medwatch.

Casirivimab/lmdevimab

The FDA issued an EUA for outpatient infusion of casirivimab/imdevimab on November 21, 2020. Casirivimab/lmdevimab is a monoclonal antibody cocktail targeting the Benefit has not been observed in patients who require oxygen or who are hospitalized.

- National allocation of casirivimab/imdevimab will be made weekly to states based on reported 7-day hospitalizations. The allocation to MSHS is limited and in order and adherence to the EUA the prescribing of casirivimab/imdevimab will be adjudicated by a multidisciplinary committee after screening and Infectious Diseases co

- Patients 12 years or older (and over $40 \mathrm{~kg}$ ) referred for casirivimab/imdevimab must have a documented direct SARS-CoV2 viral test (antigen or PCR), symptoms c at high risk for progressing to severe COVID-19. These high-risk conditions are described in the fact sheet for health care providers.

Dosing:

$1200 \mathrm{mg}$ of casirivimab with $1200 \mathrm{mg}$ of imdevimab $\times 1$ dose infused over 1 hour

Caution:

Monitor for infusion reactions and/or anaphylaxis for 1 hour after infusion

- $\quad$ Adverse events should be reported to FDA Medwatch.

$\underline{\text { Dexamethasone }}^{11-13}$

- Dexamethasone is recommended in patients with confirmed COVID-19 who require supplemental oxygen including those who require mechanical ventilation. Cortic to be beneficial in COVID-19 patients who do not require respiratory support and use in this population could be potentially harmful.

- The benefit of dexamethasone was observed in patients $>7$ days out from symptom onset.

- Dexamethasone prescribed specifically for the treatment COVID-19 should not be continued after discharge unless the patient is on chronic corticosteroid therapy.

Dosing:

Dexamethasone $6 \mathrm{mg}$ PO or IV q 24 hours for up to 10 days

Alternative corticosteroids (dose equivalent to dexamethasone): Methylprednisolone $32 \mathrm{mg}$ IV q 24 hours, Hydrocortisone $160 \mathrm{mg}$, or Prednis one 40 mg PO q 24 hours 1

Caution:

- Monitor for hyperglycemia and secondary infections.

$\underline{\text { Remdesivir }}^{14,16}$

- Exclusions for initiation and continuation: eGFR $<30 \mathrm{~mL} / \mathrm{min}, \mathrm{ALT}>5 \times$ ULN

- Consult Infectious Diseases for consideration for remdesivir therapy. The approval of remdesivir, which is non-formulary, will be determined by a multidisciplinary cc

- Use of remdesivir in pediatric patients ( $<12$ years of age) and patients weighing $<40 \mathrm{~kg}$ would be considered off-label use of remdesivir. Use of the lyophilized pow patients weighing $\geq 3.5 \mathrm{~kg}$ is available under an emergency use authorization. Due to the lack of data in adults $<40 \mathrm{~kg}$, using the EUA to document the off-label use

Remdesivir was FDA-approved for the treatment of COVID-19 on October 22, 2020 in hospitalized patients 12 years of age and older weighing at least 40 kg. The Adapti (ACTT-1) is a randomized placebo-controlled trial. In this trial hospitalized patients with lab-confirmed COVID-19 on low-flow oxygen had shorter median symptom duratio improved 29-day survival (HR for death 0.3 ). The trial was not powered to evaluate for differences in recovery time or mortality in patients receiving non-invasive ventilatio combined data from four trials including ACTT-1. In the analysis, low and high flow oxygen were combined and did not demonstrate a mortality benefit.

Dosing:

Patients $\geq 40 \mathrm{~kg}: 200 \mathrm{mg}$ IV on day 1 then 24 hours later start $100 \mathrm{mg}$ IV q $24 \mathrm{~h}$ for 4 days for a total duration of 5 days ${ }^{16}$ or until hospital discharge, whichever is soone hospitalized solely to complete course of remdesivir if discharge is appropriate.

Caution:

- Hepatic function tests should be checked prior to initiating remdesivir and daily. Elevation in transaminases have been observed in clinical trials including in both COVID-19. Hepatic function tests should be checked prior to initiating remdesivir and daily.

- Remdesivir should be discontinued if ALT > 5 times the upper limit of normal or if there is signs and symptoms of liver inflammation (e.g., increased bilirubin, alki

- Remdesivir should be discontinued if patient's eGFR $<30 \mathrm{~mL} / \mathrm{min}$.

- Adverse events should be reported to FDA Medwatch. 
Medications NOT currently recommended for the treatment of SARS-CoV2 (COVID-19):

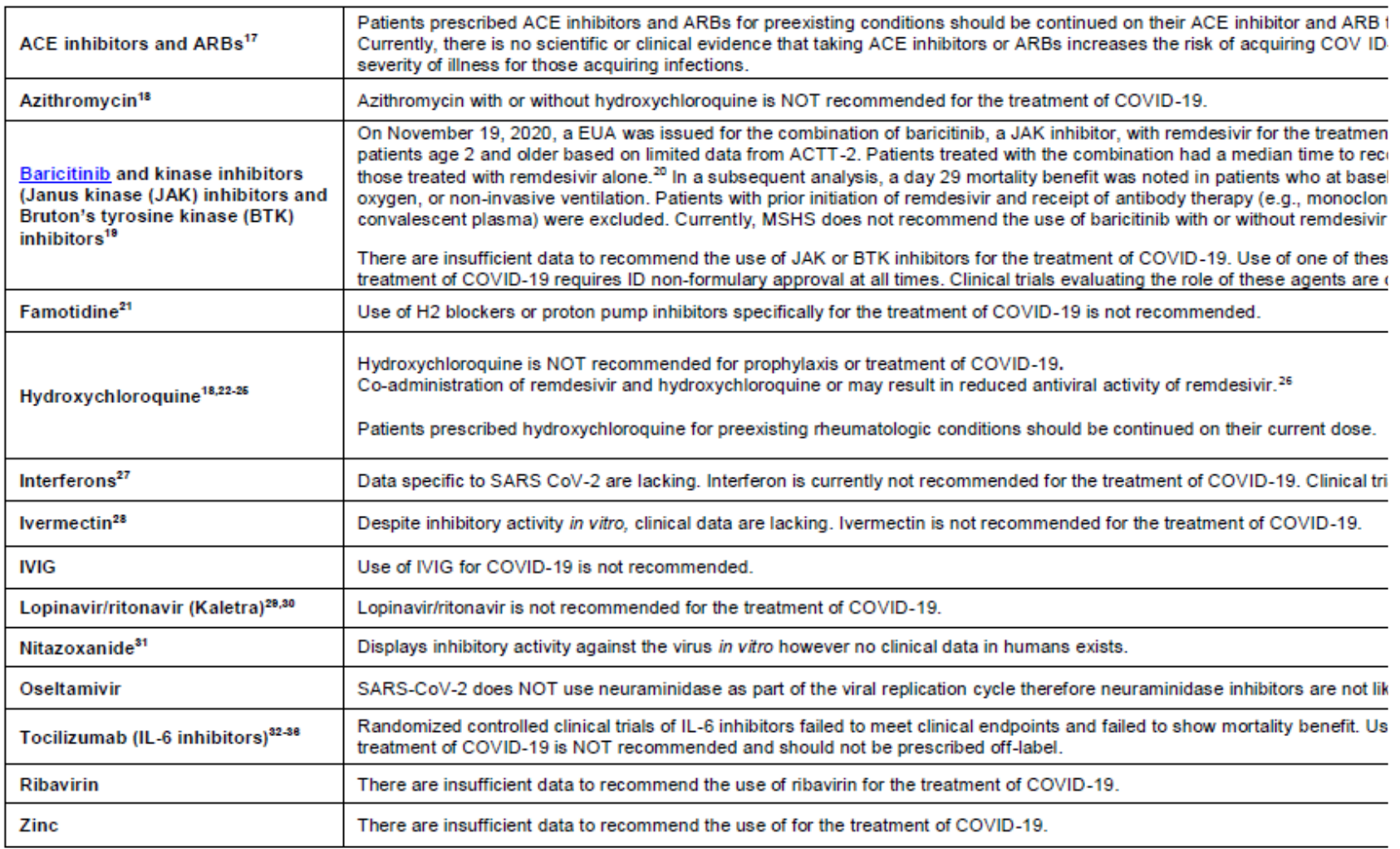




\section{MANAGEMENT OF ACUTE HYPOXEMIC RESPIRATORY FAILURE ON GENERAL INPATIENT FLOORS}

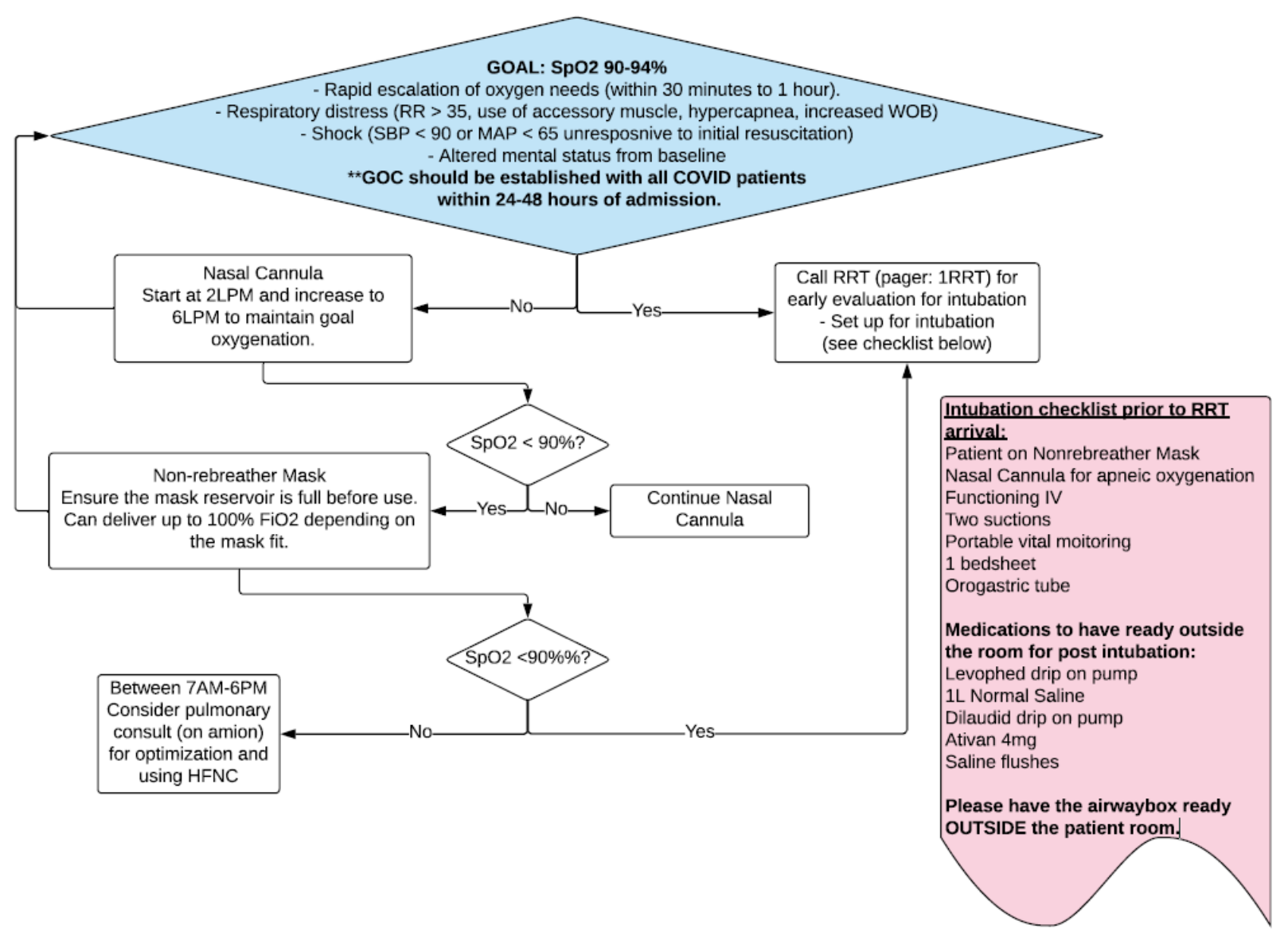




\section{MSHS COVID-19 AIRWAY MANAGEMENT GUIDE}

\section{Preparation:}

1. Respiratory Therapy should prepare the ventilator in the room prior to intubation

2. Take only the things that you need with you into the room, but make sure to take everything you need

3. Prepare medications and intubation equipment outside of the patient's room

4. Suggested hypnotic agent and succinylcholine $1-1.5 \mathrm{mg} / \mathrm{kg}$, or rocuronium $1.2 \mathrm{mg} / \mathrm{kg}$

5. Verify intravenous access

6. See equipment checklist

7. Have a dedicated provider outside the room not in PPE to hand additional equipment/medications that may be needed and to come in to assist if needed

\section{Airway Management:}

- Patients can be started on nasal cannula and titrated up to non-rebreather with a goal of $\mathrm{SpO} 2$ around $90 \%$

- Preferable in a negative pressure room but if not available can use in a room with a door with all providers wearing N95 and face shield and a sign on the door

- A trial of HFNC starting at $100 \%$ and titrate Flow for goal SpO2 $>90 \%$, surgical masks should be placed over HFNC

- CPAP/BiPAP with viral filter also can be used, again starting at 5-10 EPAP and if needed can add 5 of IPAP while watching to make sure tidal volumes are $<6-8 \mathrm{cc} / \mathrm{kg}$ of IBW

- Decision to intubate these patients needs to be carefully weighted in regard to risk vs benefit

- While it is important to not expose patients to the risk and increased mortality of intubation it is also important not to wait too long before intubating the patient

- Indications for consideration of intubation:

$\circ$ worsening mental status

0 increasing hypercapnia not resolved with NIV

- Refractory hypoxemia $\mathrm{SpO} 2<85 \%$ for extended periods of time without recovery on NIV

- Increased WOB and tachypnea not responsive to NIV

\section{Personnel:}

1. The provider on the team with the most intubation experience should intubate the patient

2. The Difficult Airway Response plan should be activated in the event of a difficult airway following the standard protocol

3. There should be no more than 3 people, ideally 2 people in the room during intubation

4. Designate a person outside the room to help with supplies if needed, and to monitor for breaches of PPE

\section{Pre-intubation:}

1. Ventilator should ideally be set up prior to intubation.

2. Advance planning and clear communication are paramount

3. If patient is not in a single patient room, separate from other patients by 6 feet using curtains or screens

4. Set up and confirm ETCO2 waveform capnography is working

5. Minimize personnel

6. All equipment/medications that are needed should be setup and brought into the room prior to the start of the procedure, see intubation check List

7. Don PPE (gown, gloves, n95 respirator, eye protection, hair cover) outside of the patient's room

\section{Intubation:}

1. Prolonged pre-oxygenation for more than 5 minutes with $100 \%$ FiO2 non rebreather (caution: expiratory ports may aerosolize secretions)

2. Most experienced provider should intubate, second provider should push medications and assist

3. Goal is Rapid Sequence Intubation (RSI)

4. Can use push dose vasopressors for post intubation hypotension if needed

5. If manual ventilation is needed, use 2 hands to provide good seal, place filter between mask and bag, and deliver small tidal volumes.

6. Do not use non-invasive ventilation if it can be avoided

7. Preferred use of video-laryngoscopy (using the device that the intubator is most experienced with and hand-held device if available) to increase the distance

8. Inflate cuff immediately after intubation

9. Doff outer gloves after intubation and prior to touching other equipment 
10. Attach filter to ETT, then the rest of the system

11. Institute mechanical ventilation on volume control mode at $6-8 \mathrm{cc} / \mathrm{kg}$ IBW flowing the ARDS net titration.

12. Use disposable stethoscope to auscultate from the patient's side

13. Avoid awake intubation (risk of aerosolizing the virus during topicalization and coughing)

14. Avoid supraglottic airway (LMA) ventilation, unless warranted for a difficult airway

\section{Post-intubation:}

1. Connect the patient to the ventilator and secure the tube

2. If need to disconnect the patient from the ventilator, put it in standby first

3. Dispose used and all disposable items that were brought into the room in trash in the room

4. Video Laryngoscope: thoroughly wipe all surfaces with peroxide wipe prior to doffing PPE making sure to fully saturate the surface following standard droplet cleaning protocols.

5. Doff PPE, ideally in anteroom if available (can remove all pieces including N95, and wash hands) but if anteroom is not present, then doff in patient's room (at least 6 feet away from the patient), except for the N95 mask, which is removed outside of the room. Hand hygiene.

6. Wipe Video Laryngoscope again with peroxide wipe after doffing PPE. After this it is ready for next patient use and can be returned to its storage location

\section{Suggested COVID-19 Airway "Go" Bag Contents, can be individualized for each department}

1. HEPA filter

2. N95 masks $\times 4$ (2 small, 2 regular)

3. Face shields $\times 2$

4. Video laryngoscope, 3 blade $\times 2,4$ blade $\times 2$

5. Stylet $\times 2$

6. Isolation gown $\times 2$

7. Waterproof (blue) gown $\times 2$

8. Sterile gown $\times 1$

9. Bouffant hat $\times 2$

10. Sterile gloves: $6.0,6.5,7.0,7.5$

11. Biohazard bag $\times 1$

\section{Intubation Check List:}

Working IV (ideally two IVs)

BVM ( \pm PEEP Valve) on Oxygen

Waveform Capnograph on BVM

Video Laryngoscope

Backup Laryngoscope

ET tube the size your plan to use and 1 size smaller

ET tube stylet

Oral airway

Bougie

LMA sized for the patient

Suction

NRB for pre-oxygenation

Nasal Cannula for Apneic Oxygenation

Paralytic (succinylcholine $1-1.5 \mathrm{mg} / \mathrm{kg}$ or rocuronium $1.2 \mathrm{mg} / \mathrm{kg}$ )

Induction Agent (Suggest ketamine $1-2 \mathrm{mg} / \mathrm{kg}$ or etomidate)

Flushes

Post intubation sedation (hydromorphone or midazolam) (setup on PCA or Pump)

Orogastric tube

Norepinephrine on pump only if needed

Bolus dose of phenylephrine 


\section{VENTILATOR MANAGEMENT OF ARDS IN COVID-19 PATIENTS}

Initial ventilator settings post intubation while in the room:

Volume Control ventilation Initial settings:

RR 16-24, higher if with baseline respiratory acidosis

$\mathrm{Vt}=6 \mathrm{cc} / \mathrm{kg}$ of IBW

Flow $50 \mathrm{~L} / \mathrm{min}$

$\mathrm{FiO} 2100 \%$

PEEP 16

- $\quad$ Titrate FiO2 first then PEEP using the ARDSNet PEEP ladder: Goal SpO2 92\%-94\% or pO2 55-80

- $\quad$ Check plateau pressure (PPlat, inspiratory pause during controlled breaths) Q8H: goal Pplat $<30$

- $\quad$ Check Driving pressure (PPlat - PEEP) Q8H: Goal < 14

- Check arterial blood gas: Goal pH 7.25-7.45

- Initial sedation target for a RASS -2 to -3 (eyes closed but responds to voice) using opiod

(Fentanyl/dilaudid) and propofol

\section{Ventilator management to achieve optimal oxygenation and ventilation during ARDS:}

\section{Key Principles:}

- Prevention of ventilator induced lung injury (VILI) using lung protective ventilation

- Prevention of ventilator dysynchrony that will worsen VILI by ensuring adequate sedation

- Permissive hypercapnea (tolerate $\mathrm{pH}$ as low as 7.25)

- Reduce oxygen toxicity secondary to hyperoxia

\section{Sedation Management:}

Goal: ventilator synchrony without stacking, double triggering, or exceeding $R R>40$

- $\quad$ Fentanyl/Dilaudid with propofol to achieve goal RASS of -2 to -3

- Benzodiazepines should only be used if patient has a contraindication for propofol (i.e. propofol infusion syndrome, hypertriglyceridemia, or pancreatitis - monitor triglycerides and lipase every 3-4 days) or max dose propofol + opiod infusion is not sufficient for sedation

- If patient continues have ventilator dyssynchrony, target RASS -4 to -5 (unarousable to voice / sternal rub)

- If with persistent dyssynchrony despite RASS -5 , paralyze with cisatracurium bolus $(0.2 \mathrm{mg} / \mathrm{kg})$ and infusion titrated to vent synchrony for $4-48 \mathrm{hr}$

\section{Oxygenation Management:}

Goal SpO2 92\%-94\% or pO2 55-80 while maintaining PPlat $<30$ or Driving pressure $<14$

- Sedation to achieve vent synchrony and improve oxygenation is essential.

- $\quad$ Titrate FiO2 and PEEP using the low PEEP ladder

\begin{tabular}{|c|c|c|c|c|c|c|c|c|}
\hline \multicolumn{9}{|c|}{ Lower PEEP/higher FiO2 } \\
\hline $\mathrm{FiO}_{2}$ & 0.3 & 0.4 & 0.4 & 0.5 & 0.5 & 0.6 & 0.7 & 0.7 \\
\hline PEEP & 5 & 5 & 8 & 8 & 10 & 10 & 10 & 12 \\
\hline $\mathrm{FiO}_{2}$ & 0.7 & 0.8 & 0.9 & 0.9 & 0.9 & 1.0 & & \\
\hline PEEP & 14 & 14 & 14 & 16 & 18 & $18-2$ & & \\
\hline
\end{tabular}

- $\quad$ Monitor PPlat and driving pressure after selecting a PEEP:

- Goal Pplat $<30$ in those with a $\mathrm{BMI}<35$

- Goal PPlat $<35$ in those with a BMI $>35$.

- If PPlat $>30$ and driving pressure $>14$, reduce $V t$ by $1 \mathrm{cc} / \mathrm{kg}$

- If PPlat $>30$ and driving pressure $<14$, monitor closely 
- If Pplat $<30$ and driving pressure is $<14$, increase $\mathrm{Vt}$ by $1 \mathrm{cc} / \mathrm{kg}$ upto to $8 \mathrm{cc} / \mathrm{kg}$ of IBW as long as

PPlat remains $<30$ and driving pressure remains $<14$

- If patient has persistent ( $>12$ hours) $\mathrm{FiO} 2$ requirements $>75 \%$ and $\mathrm{P}: \mathrm{F}<150$, consider prone position ventilation

Ventilation Management:

Goal: Low tidal volume ventilation (4-6cc/kg of IBW) while allowing for some permissive hypercapnea ( $\mathrm{pH} 7.25-$ 7.45). Tidal volumes should not exceed $8 \mathrm{cc} / \mathrm{kg}$ of IBW.

- Monitor blood gases $\sim 30$ minutes after titrating the ventilator and at least once per shift

- Decrease RR if $\mathrm{pH}>7.45$

- If $\mathrm{pH}$ is $<7.25$, increased $\mathrm{RR}$ up to 35 until $\mathrm{pH} 7.25-7.35$

- If $\mathrm{pH}$ is persistent below 7.25 despite adequate vent synchrony (comatose/paralyzed) and increasing $\mathrm{Vt}$ (as permitted by plateau and driving pressures as described in Oxygenation section), initiate prone ventilation. Please email \# Prone or obtain a prone consult.

Fluid management: Maintain euvolemia to net negative fluid balance with the assistance of diuretics and renal replacement therapy as indicated.

\section{Adjuvant therapies:}

- Consider inhaled pulmonary vasodilators (inhaled epoprostenol) for refractory hypoxemia $(\mathrm{pO} 2<55)$ if patient is not responding to prone ventilation.

- Initiate ECMO consultation for P:F $<80$ despite all the above interventions. Please see ECMO guidelines

For more information about different models of critical care, critical care-capable, subacute ventilator models and their respective capabilities:

https://www.mountsinai.org/files/MSHealth/Assets/HS/About/Coronavirus/Ventilator-Quick-Reference.pdf 


\section{GENERAL MANAGEMENT OF COVID PATIENTS IN THE ICU}

\section{Laboratory:}

On admission:

- $\quad$ CBC with differential (CBC)

- Complete metabolic panel (CMP), Magnesium, Phosphorus

- Arterial blood gas (ABG)

- Troponin

- B-type natriuretic protein (BNP)

- Inflammatory markers: Lactate dehydrogenase (LDH), Ferritin, C-reactive protein

- D-dimer and fibrinogen

- $\quad$ PT and PTT

- Creatinine kinase (CPK)

- Erythrocyte sedimentation rate (ESR)

- Procalcitonin

- Viral Hepatitis panel

- Ella - Cytokine Release Panel

- Type and Screen

Daily: CBC, CMP, Magnesium, Phosphorous, LDH, CPK, ESR, CRP, Ferritin, PT and PTT, D-dimer, Fibrinogen

Intermittent: Type and Screen as needed, Triglycerides and Lipase Q3 days if on propofol

\section{Imaging:}

- Portable CXR to confirm tubes and line placements

- Daily CXR imaging discouraged unless indicated for clinical decompensation

- CT chest routinely to diagnose COVID-19 is not indicated

- Point of Care Ultrasound to assess for lung sliding, B-lines, pleural fluid preferred methods of imaging while in ICU

\section{Daily ICU Management}

Nutrition

Management of electrolytes: Hypernatremia, Hyperkalemia

GI Prophylaxis

DVT Prophylaxis

Oral care and eye care

HOB elevation

Appropriate use and discontinuation of central lines and foleys as needed

Daily communication with family 


\section{ADULT VV ECMO IN COVID-19 PATIENTS WITH SEVERE} ARDS

\section{Indications for ECMO:}

ECMO for hypoxemic respiratory failure is indicated for patients who despite optimization of ventilator support have ongoing refractory respiratory failure.

COVID-19 confirmed patients who have not been on ventilators for more than 7 days and meet the criteria for refractory severe ARDS as defined by:

- $\mathrm{PaO} 2 / \mathrm{FiO} 2$ ratio $<50$ on $\mathrm{FiO} 2>90 \%$ for $>3$ hours or

- $\mathrm{PaO} 2 / \mathrm{FiO} 2$ ratio $<80$ on $\mathrm{FiO} 2>90 \%$ for $>6$ hours.

2. Before consideration of ECMO ventilator management should be optimized utilizing:

- Low tidal volumes $<4-6 \mathrm{ml} / \mathrm{kg}$

- $\quad$ Target plateau $<30 \mathrm{~cm} \mathrm{H} 2 \mathrm{O}$

- Attempt recruitment maneuvers if indicated

- $\quad$ Titration of PEEP to optimize PaO2/FiO2 with PEEP in range of $16-22 \mathrm{cmH} 2 \mathrm{O}$ (high PEEP ladder)

- Optimal sedation with RASS -4 to -5 and if still asynchronous paralyzed for at least $4 \mathrm{hr}$ to max $48 \mathrm{hrs}$

- Restrictive fluid strategy to avoid volume overload and try to maintain negative fluid balance

- Attempt to optimize oxygenation with inhaled Flolan/Nitric oxide. If ineffective discontinue.

- Attempt prone positioning to improve oxygenation and lung compliance before considering ECMO

3. Absolute contraindications:

- Severe multi-organ failure

- Irreversible Neurologic injury

- Active malignancy with poor prognosis

- Active Intracranial bleed or other absolute contraindications to anticoagulation

- Patient refuses consent

- Documented severe dementia or moribund state

4. Relative contraindications:

- Age $>50$

- Weight $>150 \mathrm{Kg}$

- Severe cardiac failure with EF $<25 \%$

- Severe pulmonary HTN with mean PAP > $50 \mathrm{mmHg}$

- Chronic respiratory illness or ventilator requirement for $>7$ days with high FiO2 requirements and high peak pressures

- Prolonged cardiac arrest with concern for neurologic damage

5. Mount Sinai Hospital (Upper East) request for VV ECMO in COVID-19 positive patients:

- All moderate to severe COVID-19 patients with ARDS will be evaluated by the Acute Respiratory Failure team - First call: Drs. Sam Acquah 201-396-9706 or Mehdi Oloomi 718-514-5331

- If not available: AMION $\rightarrow$ Institute of Critical Care Medicine $\rightarrow$ COVID-19 $\rightarrow$ ECMO on call attending

- On call physician takes all info, ensures best practices for ARDS management being done and presents to ECMO multidisciplinary group on call

- If patient meets criteria, location and timing of ECMO will be discussed

- All ECMO decisions for these patients will be approved by ICCM leadership

6. Other MSHS request for VV ECMO for COVID-19 positive patients:

- All calls should go through the transfer center 646-605-5902

- VV ECMO calls will be handled by VV ECMO team

- On call physician takes all info, ensure best practices for ARDS management being done and presents to necessary ECMO multidisciplinary group on call

- if deemed an ECMO candidate, attempts must be made to stabilize patient and transfer to Mount Sinai Upper East Side as soon as possible

- At this time no outside cannulation - only patients that can be safely transferred will be considered for ECMO 


\section{PUI / COVID-19 POSITIVE CARDIAC ARREST GUIDE (FOR FLOOR / ICU CODES)}

Important Things to Consider Before ACLS

- Enter the room after donning PPE - use N95 mask, face shield, hat, gown, double gloves, and other equipment as indicated.

Minimize staff and throughput within the room. Do not enter the room if you are not needed.

Use automated external compression device (LUCAS) if available.

If patient is already intubated: perform CPR on the ventilator VC mode and $\mathrm{FiO} 2100 \%$.

If the patient is not intubated, utilize a non-rebreather for oxygenation during CPR with a face mask under the non-rebreather.

The airway should be prioritized once the intubation team arrives.

Chest compressions must be held during endotracheal intubation to minimize aerosolization.

The room door should be closed all the time.

Review advanced directives and explore goals of care as appropriate before and during ACLS.

Team Members ( $\max 5)$ in room, all wearing PPE:

1. Cardiac Arrest Leader

2. RN N1: Medication administration and recording.

3. RN or MD: CPR

4. RN or MD: CPR (If not using LUCAS)

5. Respiratory therapist: Only if the patient requires intubation, Use ONLY two person bag mask ventilation technique to ensure a seal. Ventilate with a Bag Valve Mask (BVM) with a HEPA filter.

Team Members (2) outside room, not wearing PPE:

1. MD, RN or PA: Remains outside the room - Wearing PPE. Supplies medications and hands off materials as well as observes for breach in PPE of providers inside the room.

\section{ACLS Process}

1. The person who identifies patient in cardiac arrest (already in the room wearing PPE)

a. Activate Cardiac Arrest notification (e.g. press "code blue button")

b. Start chest compressions

2. 2nd person to arrive:

a. Bring cardiac arrest cart and intubation box outside the room

b. Don PPE and enter the room

c. Place backboard

d. Bring defibrillator into the room and Place Zoll pads

e. check appropriate IV access

3. 3rd person to arrive:

a. Don PPE

b. Assist critical care MD in setting up intubation equipment (if the patient is not already intubated).

c. Brings ACLS medications into the room per code leader. o Consider: epinephrine $\times 5$; bicarb $\times 2$; calcium $\times 1$; flushes $\times 10$

d. Assist with CPR, if LUCAS is not available

4. first Critical Care MD to arrive

a. Don PPE 
b. Identified as a Code leader and assigns responsibilities.

c. Manage airway if required

Intubating during code:

**Follow standard ACLS protocol

Because the most likely cause of the cardiac arrest in these patients would be a hypoxic respiratory failure, we recommend inserting an endotracheal tube as soon as possible (Follow the Mount Sinai Health System Airway Management Guide: Appendix 1).

- A Respiratory therapist is required in the room only if the patient requires endotracheal intubation.

- Do not perform endotracheal intubation during active chest compressions. When ready to intubate, chest compressions must be held.

1. Intubate using video-laryngoscope

2. Inflate the balloon

3. Place a HEPA filter between ETT and vent.

4. Directly connect patient to the ventilator. If a ventilator is not available, attach endotracheal tube with a filter to an BVM.

Note: If the patient requires ventilation during the intubation process only use a 2 person ventilation technique with the BVM and a HEPA filter. One person uses both hands around the mask to develop a seal with the patients face and the other person squeezes the bag. This will ensure a proper seal and minimize aersolization.

\section{Post-CPR:}

- Exit room

- Doff PPE

- Debrief 